\title{
Labor income taxes in an economic federation with proportional membership fees
}

\section{Tomas Sjögren ${ }^{1}$}

Published online: 9 April 2019

(c) The Author(s) 2019

\begin{abstract}
A significant part of the revenue in the EU budget is raised via a GNI-based resource. The purpose of this paper is to use a stylized model of an economic federation to analyze how this way of raising funds to the central authority affects the labor income taxes implemented by the lower-level governments. This question is analyzed both when the federal fee is proportional to GNI and proportional to GDP. One key result is that if the government in a lower-level jurisdiction acts as a Nash follower vis-a-vis the other governments in the public sector, then there is an incentive to implement a higher tax on labor. Another is that if the lower-level government is able to exercise decentralized leadership vis-à-vis a federal government which is concerned with redistribution, then the incentive structure underlying the taxation of labor is independent of how the federal government collects its revenue.
\end{abstract}

Keywords Efficiency · Optimal taxation · Economic federation

JEL Classification $\mathrm{H} 21 \cdot \mathrm{H} 41 \cdot \mathrm{H} 70$

\section{Introduction}

There is a large literature that deals with optimal taxation and public expenditure in the context of economic federations. The bulk of this literature has some common features. One is the assumption that the central authority raises revenue, either via lump-sum fees imposed on the lower-level governments, or by taxing some lower-

Helpful comments from two anonymous referees and research grants from the Bank of Sweden Tercentenary Foundation, the Swedish Council for Working Life and Social Research, and the Swedish Tax Agency are gratefully acknowledged.

\footnotetext{
$\bowtie$ Tomas Sjögren

tomas.sjogren@umu.se

1 Department of Economics, Umeå School of Business and Economics, Umeå University, 90187 Umeå, Sweden
} 
level tax base. Another is the assumption of centralized leadership whereby the central authority is able to commit to its policy, while the lower-level governments cannot do that. ${ }^{1}$ Although these assumptions are well suited to describe the institutional settings within most sovereign countries, they do not capture some key characteristics of the European Union (EU).

One characterizing feature of EU is that the revenue available for the central authority does not arise from lump-sum fees imposed on the lower-level governments. Instead, the bulk of the revenue at the EU level comes from two main sources: own resources and other revenue. The own resources constitutes the major source of income within the general EU budget, and it is made up of three categories. (i) Traditional own resources which mainly consist of custom duties on imports from outside the EU and sugar levies, (ii) a VAT-based resource which is a standard percentage levied on a value-added-tax (VAT) base in each EU country and (iii) a GNI-based resource where a standard percentage is levied on the gross national income (GNI) of each EU country. The GNI-based resource is the dominant source of revenue and represents about $60 \%$ of total own resources. ${ }^{2}$

Another feature of EU is that it is often defined as a political union which is characterized by decentralized leadership. ${ }^{3}$ This notion implies that the lower-level (national) governments act as first movers vis-à-vis the upper level. There are several arguments for why EU exemplifies a decentralized economic federation. One is that the member states have a significant influence over EU policy via the council of Ministers (which is made up of ministers from the member state governments). Another is that the central authority redistributes income (e.g., via Structural and Cohesion Funds) conditional on the national policies. This makes it possible for the governments in the member countries to act strategically as first movers vis-à-vis the central authority. ${ }^{4}$ A third argument is that EU is still in the process of being developed, while the national governments may already have pre-committed to policies based on domestic objectives. 5

These observations imply that a theoretical analysis of the incentive structure underlying public policy in a fiscal union of EU type should incorporate (i) a system of financing for the central authority where the revenue is proportional to some measure of the local jurisdictions' national income and (ii) decentralized leadership. Although there are some earlier studies that analyze the incentive structure in an economic federation characterized by decentralized leadership, there are no previous studies which address the question of how a proportional revenue system affects the incentives facing the lower-level governments when they implement their tax and expenditure policies. The purpose of this paper is therefore to set up a stylized model to analyze how proportional membership fees affect the lower-level governments' incentive to tax labor

\footnotetext{
1 See, e.g., Boadway and Keen (1996), Dahlby (1996), Boadway et al (1998), Sato (2000), Aronsson and Wikström (2001), Dahlby and Wilson (2003) and Aronsson and Blomquist (2008).

2 As for the category other revenue, it constitutes a minor source of income within the general EU budget and consists mainly of revenue accruing from the administrative operations of EU institutions (such as proceeds from the sale of property, the supply of services and from bank interest).

3 See, e.g., Silva and Caplan (1997).

4 This has been emphasized by several authors. See, e.g., Köthenbürger (2004) and Caplan and Silva (2011).

5 See, e.g., Aronsson et al (2006) and Aronsson (2010).
} 
income. This analysis is conducted both when the lower-level governments act as Nash followers and therefore treat the choices made by the other governments in the federation as exogenous, and when the lower-level governments are able to exercise decentralized leadership vis-à-vis the central authority. The motive for focusing on labor income taxation is that labor income taxes constitute a major source of revenue for the governments in many countries.

A consequence of having a proportional revenue system is that it (to some degree) makes it possible to tax a given tax base in different ways. The reason is that GNI (among other things) is made up of labor income earned both at home and abroad. This means that when the federal fee is proportional to GNI, then this (to some extent) constitutes a residence-based tax on labor. If the local governments are restricted to source-based taxation, it follows that a similar tax base (labor) is taxed in different ways (residence based vs source based) depending on the level of government. This feature is novel compared with earlier studies, where it is usually assumed that different levels of government share a common tax base which is taxed in a similar way.

A theoretical analysis along the lines outlined above makes it possible to address several empirically relevant questions. Does a federal revenue mechanism that is proportional to a measure of the local jurisdictions' national income provide the local governments with an incentive to implement a nonzero (i.e., distortionary) marginal tax on labor income? Will the lower-level governments respond differently if the fee paid to the central authority is proportional to the local jurisdictions' gross domestic products (GDP) or proportional to the local jurisdictions' gross national incomes (GNI)? Is there a qualitative difference between the policy implemented by a local government which exercises decentralized leadership, and the policy implemented by a local government which acts as a Nash follower (vis-à-vis the other governments in the federation), in the presence of a proportional federal revenue mechanism? How does labor mobility affect the results?

To address these questions, we set up a model of an economic federation made up of two member states and a federal government. The federal government raises revenue via fees that are either proportional to the member states' GDP or GNI, and the federal government uses its revenue to finance an exogenous expenditure requirement and (except in a special case) to redistribute resources between the two member states. The federal fees are paid by the state governments, and each state government raises its revenue by taxing the labor income and the profit income earned within the state. There is no restriction on the profit tax. This implies that if the state government chooses to implement a nonzero tax on labor income, then this is a consequence of optimization instead of some arbitrary restriction imposed on the government. ${ }^{6}$

The approach used in this paper makes it possible to analyze how the local governments will respond to the incentive structure implied by the use of a proportional federal revenue mechanism. The key results can be summarized as follows: (i) a proportional federal revenue mechanism provides the local governments with an incentive to implement a higher tax on labor if the local governments act as Nash followers.

\footnotetext{
${ }^{6}$ Or put differently, since each state government can use a lump-sum tax to raise funds, there is no fiscal motive for implementing a tax on labor. If a state government nevertheless chooses to do so, then this reflects a motive to achieve a particular goal (e.g., to use the tax to influence the size of the fee paid to the federal government).
} 
(ii) The design of the marginal tax on labor income differs depending on whether the federal fee is proportional to GDP or GNI. (iii) If a state government is able to exercise decentralized leadership vis-à-vis the federal government, then the incentive structure underlying the taxation of labor is independent of how the federal government collects its revenue. (iv) If the federal government is not concerned with redistributing income between the two member states, then a proportional federal revenue mechanism provides a decentralized leader with a distinct motive to implement a positive tax on labor income.

Only a few earlier studies have examined the incentive structure in a federation with decentralized leadership. Köthenbürger (2004) analyzes tax competition under decentralized leadership, and he considers a two-layer fiscal union with mobile capital where each member state chooses its capital tax to finance the provision of a local public good, while the federal government uses lump-sum transfers to redistribute resources between the member states. His main finding is that horizontal fiscal externalities are neutralized by ex post federal policy. Aronsson (2010) analyzes local public good provision and redistribution in an economic federation where the public sector is not able to observe the ability of the individual agents. Aronsson shows how federal ex post redistribution modifies the provision of the local public good and the design of the optimal income tax. Caplan et al. (2000) study federal lump-sum redistribution and spillover effects of local public goods. With redistribution carried out by the central authority that is directed to the private sector, it is shown that decentralized leadership gives rise to an efficient outcome. Caplan and Silva (2011) analyze decentralized provision of an impure public good where the central authority provides matching grants and redistributes income after the lower-level jurisdictions have determined their contributions to the impure public good. Labor is assumed to be imperfectly mobile, and it is shown that an equilibrium with positive contributions to the impure public good is Pareto efficient. ${ }^{7}$ Finally, in a model of tax competition, Silva (2017) shows that federal equalization schemes provide local governments with correct incentives in the sense that they prevent the phenomenon known as "race to the bottom."

Another issue that has been addressed in the context of decentralized leadership is environmental policy. ${ }^{8}$ Aronsson et al. (2006) consider a model where the central authority sets emission targets to be implemented by the lower-level jurisdictions. The governments in the lower-level jurisdictions face a mixed tax problem, and it is shown how the lower-level governments use their policy instruments to influence the emission target imposed by the central authority. It is also shown that this provides an incentive for implementing a distortionary tax on labor and that the commodity tax does not satisfy the additivity property.

The outline of the paper is as follows: In Sect. 2, we characterize the private sector and the federal government. In Sect. 3, we characterize the policy implemented by the local governments when labor is immobile, while the policy implemented when labor is mobile is characterized in Sect. 4. Section 5 concludes.

\footnotetext{
${ }^{7}$ See also Köthenbürger (2007).

8 See also Silva and Caplan (1997) and Caplan and Silva (2000).
} 


\section{The basic model}

Consider an economic federation made up of two member states, denoted 1 and 2 , and a federal government. The production side in state $i=1,2$ is made up of identical competitive firms which produce a homogenous good which without cost can be transformed either into a private good or into a local public good. The number of firms in each state is normalized to one, and the firm uses labor and a fixed factor in the production process. The production function in state $i$ is given by $Y_{i}=F_{i}\left(L_{i}\right)$, where $Y_{i}$ is aggregate domestic output, and $L_{i}$ is the amount of labor employed in the production process. The production function satisfies $F_{i}^{\prime \prime}\left(L_{i}\right)<0<F_{i}^{\prime}\left(L_{i}\right)$, and the profit $\pi_{i}=F_{i}\left(L_{i}\right)-w_{i} L_{i}$ is compensation to the fixed factor. The first-order condition for profit maximization w.r.t. labor is $w_{i}=F_{i}^{\prime}\left(L_{i}\right)$, and this equation implicitly defines the demand for labor as a decreasing function of the wage; $L_{i}^{d}\left(w_{i}\right)$.

Each state consists of identical consumers, and we normalize the number of consumers in each state to one. The preferences of consumer $i$ (the consumer residing in state $i)$ are captured by the utility function $U_{i}=u\left(c_{i}, z_{i}\right)+\phi\left(g_{i}\right)$, where $c_{i}$ is consumption, $z_{i}$ leisure and $g_{i}$ a local public good provided by government $i$ (the local government in state $i$ ). The utility function is increasing and strictly concave in each argument, and leisure is determined by $z_{i}=h-l_{i}$, where $h$ is a fixed time endowment, and $l_{i}$ is the total number of hours supplied by consumer $i$. To simplify the calculations to be made below, it is convenient if the consumer's labor supply function is only a function of the after-tax wage. ${ }^{9}$ This will arise if, for example, $u\left(c_{i}, h-l_{i}\right)$ is quasilinear in $c_{i}$ or if this sub-utility function can be written as $u\left[c_{i}-e\left(l_{i}\right)\right]$, where $e\left(l_{i}\right)$ is an increasing and convex function of $l_{i}$.

If labor is allowed to move freely between the two states, then consumer $i$ may work both at home (in state $i$ ) and abroad (in state $j=1,2$ where $j \neq i$ ). The beforetax hourly wage in state $i(j)$ is denoted $w_{i}\left(w_{j}\right)$, and labor income is taxed at the source. This means that if consumer $i$ partially works in state $j$, then the part of labor income that is earned in state $j$ is also taxed in state $j$. The (marginal) tax on the labor income earned in state $i(j)$ is denoted $t_{i}\left(t_{j}\right)$, and the after-tax wages in states $i$ and $j$ are denoted $w_{i}^{n}=\left(1-t_{i}\right) w_{i}$ and $w_{j}^{n}=\left(1-t_{j}\right) w_{j}$, respectively. Labor mobility, in turn, ensures that the after-tax wages will be equalized when the labor market is in equilibrium; $w_{i}^{n}=w_{j}^{n}$. If this condition would not be satisfied, then both consumer $i$ and consumer $j$ would prefer to work in the state where the after-tax wage is highest. However, if the production functions satisfy

$$
\lim _{L_{i} \rightarrow 0} w_{i}=F^{\prime}\left(L_{i}\right) \rightarrow \infty, \quad \lim _{L_{j} \rightarrow 0} w_{j}=F^{\prime}\left(L_{j}\right) \rightarrow \infty
$$

then corner solutions can be ruled out.

The profit earned by the firm in state $i$ accrues to the consumer residing there. This means that the private budget constraint is given by $c_{i}=w_{i}^{n} l_{i}+\pi_{i}-T_{i}$, where $T_{i}$ is a lump-sum tax that the local government can impose on the consumer residing in state $i$. Substituting the private budget constraint into the sub-utility function $u\left(c_{i}, h-l_{i}\right)$ and

\footnotetext{
9 This property is not necessary for the results derived in this paper; it only serves to simplify the calculations to be carried out below.
} 
maximizing the resulting expression w.r.t. $l_{i}$ produce the standard first-order condition for labor supply

$$
\left(1-t_{i}\right) w_{i} \frac{\partial u\left(c_{i}, h-l_{i}\right)}{\partial c_{i}}=\frac{\partial u\left(c_{i}, h-l_{i}\right)}{\partial z_{i}}
$$

As mentioned above, it is assumed that the labor supply is only a function of the after-tax wage, i.e., $l_{i}=l\left(w_{i}^{n}\right)$, where $\mathrm{d} l_{i} / \mathrm{d} w_{i}^{n}>0$.

The public sector is made up of the local governments in the two member states plus the federal government. Two types of interaction between the local governments and the federal government are considered. One is a noncooperative Nash equilibrium where all decision makers in the public sector (the federal government and the two local governments) treat the choices made by the other governments in the public sector as given. The other is a decentralized economic federation where the federal government treats the choices made by the local governments as exogenously given but where at least one of the local governments is able to act as a strategic leader vis-a-vis the federal government. In the latter scenario, the decentralized leader acts as a first mover vis-à-vis the federal government, thereby recognizing that it can use its policy instruments to influence the decisions made by the federal government. However, each local government treats the choices made by the other local government as exogenous. ${ }^{10}$

The federal government collects revenue from the local jurisdictions to achieve redistribution and to finance an exogenously given expenditure requirement, $\bar{G}$. The fee paid by each local government is proportional to that state's national income. Two measures of national income will be used, GDP and GNI. The gross domestic product in state $i$ is determined by $\mathrm{GDP}_{i}=Y_{i}$, while the gross national income is equal to aggregate domestic output plus net factor income paid to/received from abroad, i.e., $\mathrm{GNI}_{i}=Y_{i}+\mathrm{FI}_{i}$, where $\mathrm{FI}_{i}=w_{j}^{n}\left(l_{i}-L_{i}\right)$. When the federal fee is proportional to GDP, the federal budget constraint is given by $\bar{G}=s_{i} \mathrm{GDP}_{i}+s_{j} \mathrm{GDP}_{j}$, but when the federal fee is proportional to GNI, then the federal budget constraint is given by $\bar{G}=s_{i} \mathrm{GNI}_{i}+s_{j} \mathrm{GNI}_{j}$, where $s_{i}\left(s_{j}\right)$ will be referred to as the federal tax rate levied on state $i(j)$.

The federal government has a utilitarian objective function, $W_{F}=U_{i}+U_{j}$, and when solving its maximization problem, the federal government recognizes that the choices of $s_{i}$ and $s_{j}$ affect the local governments' abilities to provide the local public goods. ${ }^{11}$ As such, the federal government recognizes that the local government's budget constraint is determined by $g_{i}=T_{i}+t_{i} w_{i} L_{i}-s_{i} \mathrm{GDP}_{i}$ when the federal fee is proportional to GDP, and determined by $g_{i}=T_{i}+t_{i} w_{i} L_{i}-s_{i} \mathrm{GNI}_{i}$ in the scenario where the federal fee is proportional to GNI. Since the federal government acts as a

\footnotetext{
10 This timing of decision making is important for the results to be derived below. If the sequence of events would be different, then the outcome could be different. For example, Mitsui and Sato (2001) consider a model where local and central governments determine their policies after individuals have made their decisions. If that approach would be applied in this model, many of the results derived below would become redundant.

11 This assumption is in line with, for example, Keen and Kotsogiannis (2002). If the federal government would not be able to see through the member states' budget constraints, then a 'top-down' externality would arise.
} 
Nash follower vis-a-vis the lower-level governments, the federal government treats the local governments' decision variables $\left(t_{i}, t_{j}, T_{i}, T_{j}\right)$ as exogenous.

\section{Optimal policy when labor is immobile}

Let us first characterize the outcome when labor cannot move between the two member states. In this situation, the equilibrium condition $w_{i}^{n}=w_{j}^{n}$ is redundant. Instead, the labor market equilibrium in state $i$ is determined by the equalization of the domestic supply of, and the domestic demand for, labor; $l_{i}\left[\left(1-t_{i}\right) w_{i}\right]=L_{i}^{d}\left(w_{i}\right)$. This equation implicitly defines the equilibrium wage as an increasing function of $t_{i}, w_{i}^{\circ}\left(t_{i}\right)$, where the super-index "o" denotes an equilibrium value in the closed economy. The equilibrium level of employment, $L_{i}^{\circ}$, is determined by $L_{i}^{\circ}\left(t_{i}\right)=L_{i}^{d}\left[w_{i}^{\circ}\left(t_{i}\right)\right]$, and this equation defines $L_{i}^{\circ}\left(t_{i}\right)$ as a decreasing function of $t_{i}$. We can then write the equilibrium profit as $\pi_{i}^{\circ}\left(t_{i}\right)=F_{i}\left[L_{i}^{\circ}\left(t_{i}\right)\right]-w_{i}^{\circ}\left(t_{i}\right) L_{i}^{\circ}\left(t_{i}\right)$ and the equilibrium consumption as $c_{i}^{\circ}\left(t_{i}, T_{i}\right)=F_{i}\left[L_{i}^{\circ}\left(t_{i}\right)\right]-t_{i} w_{i}^{\circ}\left(t_{i}\right) L_{i}^{\circ}\left(t_{i}\right)-T_{i}$.

\subsection{Optimal policy under cooperation}

It is useful to have a benchmark with which we can compare the results to be derived below. In line with much of the literature on fiscal federalism, the cooperative equilibrium will be used as the benchmark. Here a central planner determines the taxes in each state $i$, which means that the central planner solves the following maximization problem

$$
\max _{s_{i}, t_{i}, T_{i}} \sum_{i}\left\{u\left[c_{i}^{\circ}\left(t_{i}, T_{i}\right), h-L_{i}^{\circ}\left(t_{i}\right)\right]+\phi\left(g_{i}\right)\right\}
$$

subject to

$$
g_{i}=T_{i}+t_{i} w_{i}^{\circ}\left(t_{i}\right) L_{i}^{\circ}\left(t_{i}\right)-s_{i} F_{i}\left(L_{i}^{\circ}\left(t_{i}\right)\right), \quad \bar{G}=\sum_{i} s_{i} F_{i}\left(L_{i}^{\circ}\left(t_{i}\right)\right)
$$

where $\mathrm{GNI}_{i}^{\circ}=\mathrm{GDP}_{i}^{\circ}=F\left[L_{i}^{\circ}\left(t_{i}\right)\right]$ holds when labor is immobile. Since the central planner can determine both the slope $\left(t_{i}\right)$ and the intercept $\left(T_{i}\right)$ of the labor income tax function in each member state, it is possible to implement any desired combination of work hours and private consumption for the consumer residing in state $i$. This implies that the central planner has a sufficient number of policy instruments at his/her disposal to implement the first best policy. ${ }^{12}$ In the Appendix, it is shown that this policy can be summarized by the following equations:

\footnotetext{
12 The ability to implement the first best policy is a feature that makes this benchmark model different compared with some other benchmark models used in the literature on fiscal federalism; see, e.g., Keen and Kotsogiannis (2002), Kotsogiannis (2010) and Sas (2017). In the latter models, the central planner lacks a sufficient number of policy instruments to implement the first best optimum. As a consequence, the benchmark outcomes in these models reflect cooperative second best equilibria.
} 


$$
\phi_{i}^{\prime}=\phi_{j}^{\prime}, \quad t_{i}=0, \quad \frac{\phi_{i}^{\prime}}{u_{c}^{i}}=1
$$

where $\phi_{i}^{\prime}=\phi^{\prime}\left(g_{i}\right), \phi_{j}^{\prime}=\phi^{\prime}\left(g_{j}\right)$ and $u_{c}^{i}=\partial u_{i} / \partial c_{i}$. The first equation in (4) implies complete redistribution in the sense that the same amount of the local public good will be provided in each member state, i.e., $g_{i}=g_{j}$. The second equation in (4) shows that there is no incentive to implement a distortionary tax on labor income since the tax revenue in member state $i$ can be raised via the lump-sum tax $T_{i}$. As for the third equation in (4), it shows that the marginal rate of substitution between public and private spending $\left(\phi_{i}^{\prime} / u_{c}^{i}\right)$ is set equal to the marginal cost of public funds (MCPF) which is one.

\subsection{Optimal policy with separate federal and local governments}

Let us now return to the case where the public sector is made up of separate federal and local governments. Beginning with the federal government, it is straightforward to show that the solution to its maximization problem, both when labor is immobile and mobile, implies that $s_{i}$ and $s_{j}$ are set so as to satisfy the first best rule $\phi_{i}^{\prime}=\phi_{j}^{\prime}$. This equation, together with the federal government's budget constraint, implicitly defines $s_{i}$ and $s_{j}$ as functions of the local governments' tax instruments; $s_{i}\left(t_{i}, T_{i}, t_{j}, T_{j}\right)$ and $s_{j}\left(t_{i}, T_{i}, t_{j}, T_{j}\right)$. These functions will be referred to as federal reaction functions, and all interpretations below will be based on the premise that $s_{i}$ and $s_{j}$ are positive.

Let us now turn to the local government in member state $i=1,2$. It chooses $t_{i}$ and $T_{i}$ to maximize the welfare function $U_{i}=u\left[c_{i}^{\circ}\left(t_{i}, T_{i}\right), h-L_{i}^{\circ}\left(t_{i}\right)\right]+\phi\left(g_{i}\right)$, subject to the budget constraint $g_{i}=T_{i}+t_{i} w_{i}^{\circ}\left(t_{i}\right) L_{i}^{\circ}\left(t_{i}\right)-s_{i} F_{i}\left(L_{i}^{\circ}\left(t_{i}\right)\right)$. In the Appendix, we solve this maximization problem both when government $i$ acts as a Nash follower vis-à-vis the federal government (and vis-à-vis the other local government), and when government $i$ exercises decentralized leadership vis-à-vis the federal government (but where government $i$ treats the choices made by the other local government as exogenous). We summarize the results as follows;

Proposition 1 Consider an economic federation made up of two member states and a federal government where the latter raises revenue from the local governments viafees that are proportional to the GDP in each member state, and where labor is immobile.

(i) In a noncooperative Nash equilibrium, the local government in state $i$ implements $\phi_{i}^{\prime} / u_{c}^{i}=1$ and $t_{i}=s_{i}$.

(ii) If the local government in state $i$ is able to exercise decentralized leadership vis-à-vis the federal government, then $\phi_{i}^{\prime} / u_{c}^{i}=2$ and $t_{i}=0$.

To interpret part (i), we first recall that the optimal policy implemented under cooperation features $t_{i}=0$. To explain why this result does not hold in the noncooperative Nash equilibrium, we conduct the following thought experiment. Assume that the local government initially has made an optimal choice of $T_{i}$ conditional on that $t_{i}$ is zero. Does the local government have an incentive to change $t_{i}$ from this initial value? To address this question, we differentiate the local government's objective function w.r.t. 
$t_{i}$ and evaluate the resulting expression at $t_{i}=0$. By using that the optimal choice of $T_{i}$ satisfies $\phi_{i}^{\prime} / u_{c}^{i}=1$, the welfare effect of an infinitesimal increase in $t_{i}$ reduces to ${ }^{13}$

$$
\left.\frac{\partial U_{i}}{\partial t_{i}}\right|_{t_{i}=0}=-\phi_{i}^{\prime} s_{i} w_{i}^{\circ} \frac{\mathrm{d} L_{i}^{\circ}}{\mathrm{d} t_{i}}
$$

where we recall that $\mathrm{d} L_{i}^{\circ} / \mathrm{d} t_{i}<0$. Equation (5) implies that if member state $i$ is a net contributor of revenue to the federal government $\left(s_{i}>0\right)$, then the local government has an incentive to implement a positive (marginal) tax on labor. The reason is that by increasing this tax from zero, employment is reduced and so is $\operatorname{GDP}_{i}=F\left[L_{i}^{\circ}\left(t_{i}\right)\right]$. The reduction in $\mathrm{GDP}_{i}$ implies that the fee paid to the federal government will be smaller (since the federal fee is proportional to GDP) which, on the margin, is welfare improving from the perspective of the local government. At the optimum, $t_{i}$ is set equal to $s_{i}$ because then the marginal distortionary effect of the tax equals the marginal benefit of reducing the fee paid to the federal government. We will refer to this as the proportional fee motive for taxing labor.

Let us now turn to part (ii) in Proposition 1. It shows that if the local government is able to exercise decentralized leadership, then it has no incentive to implement a distortionary tax on labor. To explain this result, we make the same thought experiment as in the preceding paragraph and assume that the government initially has made an optimal choice of $T_{i}$ conditional on $t_{i}=0$. A key difference here is that the decentralized leader recognizes the federal reaction function $s_{i}\left(t_{i}, T_{i}, t_{j}, T_{j}\right)$. In the Appendix, it is shown that $\partial s_{i} / \partial T_{i}=0.5 / Y_{i}$, and when we use this result in the decentralized leader's first-order condition for $T_{i}$, it follows that $\phi_{i}^{\prime} / u_{c}^{i}=2$. This reflects that if the local government, ceteris paribus, increases its tax revenue via $T_{i}$, then the federal government will respond by collecting half of that revenue so as to maintain complete redistribution between the member states. Therefore, when the local government exercises decentralized leadership, it recognizes that $\mathrm{MCPF}_{i}=2$. Does the local government in this situation have an incentive to let $t_{i}$ deviate from zero? To address this question, we differentiate the local government's objective function w.r.t. $t_{i}$ and evaluate the resulting expression at $t_{i}=0$, while we at the same time recognize that $\phi_{i}^{\prime} / u_{c}^{i}=2$. This produces ${ }^{14}$

$$
\left.\frac{\partial U_{i}}{\partial t_{i}}\right|_{t_{i}=0}=-s_{i} \phi_{i}^{\prime} w_{i}^{\circ} \frac{\mathrm{d} L_{i}^{\circ}}{\mathrm{d} t_{i}}+\phi_{i}^{\prime} \frac{1}{2} w_{i}^{\circ} L_{i}^{\circ}-\left.\phi_{i}^{\prime} Y_{i} \frac{\partial s_{i}}{\partial t_{i}}\right|_{t_{i}=0}
$$

Since the first term on the right-hand side (RHS) is the proportional fee motive to tax labor, it follows that two additional terms appear on the RHS of (6) compared with Eq. (5). The first additional term [the second term on the RHS of (6)] is positive and reflects that the local government has a higher marginal valuation of additional

\footnotetext{
13 Equation (5) is derived by differentiating the objective function $U_{i}$, which is defined in Eq. (A18) in the Appendix, w.r.t. $t_{i}$. To simplify the resulting expression, we use that $\mathrm{dGNI}_{i}^{\circ} / \mathrm{d} t_{i}=w_{i}^{\circ}\left(\mathrm{d} L_{i}^{\circ} / \mathrm{d} t_{i}\right)$ when labor is immobile. We also use that $l_{i}^{\circ}=L_{i}^{\circ}, \phi_{i}^{\prime} / u_{c}^{i}=1, t_{i}=0$ and $\partial s_{i} / \partial t_{i}=0$. Substituting these definitions into the expression for $\partial U_{i} / \partial t_{i}$ produces Eq. (5).

${ }^{14}$ Equation (6) is derived by differentiating Eq. (A18) in the Appendix, w.r.t. $t_{i}$. To simplify the resulting expression, we use that $\mathrm{dGNI}_{i}^{\circ} / \mathrm{d} t_{i}=w_{i}^{\circ}\left(\mathrm{d} L_{i}^{\circ} / \mathrm{d} t_{i}\right)$. We also use $\mathrm{GNI}_{i}^{\circ}=F\left[L_{i}^{\circ}\left(t_{i}\right)\right], l_{i}^{\circ}=L_{i}^{\circ}, t_{i}=0$ and Eq. (A27) in the Appendix to simplify the expression for $\partial U_{i} / \partial t_{i}$. This produces Eq. (6).
} 
funds than the consumer $\left(\phi_{i}^{\prime}>u_{c}^{i}\right)$. This implies that raising additional revenue via a tax on labor will be welfare improving. The second additional term reflects that the decentralized leader takes into account how the federal government will respond to an increase in the labor tax from the initial value $t_{i}=0$. It can be shown that ${ }^{15}$

$$
\left.\frac{\partial s_{i}}{\partial t_{i}}\right|_{t_{i}=0}=\frac{1}{Y_{i}}\left(\frac{1}{2} w_{i}^{\circ} L_{i}^{\circ}-s_{i} w_{i}^{\circ} \frac{\mathrm{d} L_{i}^{\circ}}{\mathrm{d} t_{i}}\right)
$$

The first term inside brackets reflects that if the local government increases its tax revenue via a higher tax on labor income, then the federal government will respond by collecting half of that additional tax revenue via a higher federal tax rate. The second term inside brackets reflects the federal government's response to the proportional fee motive to tax labor at the local level. When $s_{i}>0$, the federal government responds by increasing the federal tax rate so as to offset the reduction in federal revenue. ${ }^{16}$ Since the local government anticipates how the federal government will respond to an increase in $t_{i}$, the proportional fee motive to tax labor vanishes under decentralized leadership. This can be seen if we substitute Eq. (7) into Eq. (6), which produces $\partial U_{i} /\left.\partial t_{i}\right|_{t_{i}=0}=0$. Hence, the decentralized leader has no incentive to let the marginal tax rate deviate from zero when labor is immobile.

\section{Optimal policy with mobile labor}

Let us now characterize the outcome when the consumer residing in member state $i$ is able to work both in state $i$ and in state $j$. With mobile labor, the labor market equilibrium is defined by the identity $l\left(w_{i}^{n}\right)+l\left(w_{j}^{n}\right)=L_{i}^{d}\left(w_{i}\right)+L_{j}^{d}\left(w_{j}\right)$. If we combine this equation with the firms' first-order conditions $w_{i}=F_{i}^{\prime}\left(L_{i}\right)$ and $w_{j}=F_{j}^{\prime}$ $\left(L_{j}\right)$, and with the equilibrium condition $w_{i}^{n}=w_{j}^{n}$, we obtain the following set of equations

$$
\begin{gathered}
0=\left(1-t_{i}\right) F_{i}^{\prime}\left(L_{i}^{*}\right)-\left(1-t_{j}\right) F_{j}^{\prime}\left(L_{j}^{*}\right) \\
0=L_{i}^{*}+L_{j}^{*}-l_{i}\left[\left(1-t_{i}\right) F_{i}^{\prime}\left(L_{i}^{*}\right)\right]-l_{j}\left[\left(1-t_{j}\right) F_{j}^{\prime}\left(L_{j}^{*}\right)\right]
\end{gathered}
$$

where the super-index “ $*$ " denotes an equilibrium value when labor is mobile. Equations (8) and (9) implicitly determine the equilibrium levels of employment in the two states, $L_{i}^{*}$ and $L_{j}^{*}$, as functions of the (marginal) tax rates; $L_{i}^{*}\left(t_{i}, t_{j}\right)$ and $L_{j}^{*}\left(t_{i}, t_{j}\right)$. In the Appendix, we show that $\partial L_{i}^{*} / \partial t_{i}, \partial L_{j}^{*} / \partial t_{j}<0$ and $\partial L_{i}^{*} / \partial t_{j}, \partial L_{j}^{*} / \partial t_{i}>0$.

\footnotetext{
15 Equation (7) is derived by using $\mathrm{GNI}_{i}^{\circ}=F\left[L_{i}^{\circ}\left(t_{i}\right)\right], t_{i}=0, \phi_{i}^{\prime \prime}=\phi_{j}^{\prime \prime}$ and $\phi_{i}^{\prime \prime} /\left(\phi_{i}^{\prime \prime}+\phi_{j}^{\prime \prime}\right)=0.5$ in Eq. (A17) in the Appendix, while we also recognize that $\partial w_{j} / \partial t_{i}$ and $\partial L_{j} / \partial t_{i}$ are redundant when labor is immobile.

${ }^{16}$ It is worth emphasizing that the federal government does not take the effects in Eq. (7) into account when it determines the federal tax rates [i.e., the terms on the RHS of Eq. (7) do not appear in the federal first-order conditions]. Instead, the responses in Eq. (7) are 'passive' and reflect how the federal government responds to a change in a variable that the federal government treats as exogenous (here the labor tax $t_{i}$ ).
} 
These partial derivatives reflect that an increase in $t_{i}\left(t_{j}\right)$ makes it less attractive to work in state $i(j)$. This leads to an outflow of labor to state $j(i)$ so that $L_{i}^{*}$ $\left(L_{j}^{*}\right)$ is smaller and $L_{j}^{*}\left(L_{i}^{*}\right)$ is larger in the new equilibrium. The equilibrium wage in member state $i$ is defined by $w_{i}^{*}\left(t_{i}, t_{j}\right)=F_{i}^{\prime}\left[L_{i}^{*}\left(t_{i}, t_{j}\right)\right]$, where the concavity of the production function, together with the properties of $L_{i}^{*}\left(t_{i}, t_{j}\right)$, implies $\partial w_{i}^{*} / \partial t_{i}>0$ and $\partial w_{i}^{*} / \partial t_{j}<0$. The equilibrium labor supply is defined by $l_{i}^{*}$ $\left(t_{i}, t_{j}\right)=l\left[\left(1-t_{i}\right) w_{i}^{*}\left(t_{i}, t_{j}\right)\right]$, whereas the equilibrium profit and consumption levels are defined by $\pi_{i}^{*}\left(t_{i}, t_{j}\right)=F_{i}\left[L_{i}^{*}\left(t_{i}, t_{j}\right)\right]-w_{i}^{*}\left(t_{i}, t_{j}\right) L_{i}^{*}\left(t_{i}, t_{j}\right)$ and $c_{i}^{*}\left(t_{i}, t_{j}, T_{i}\right)=$ $\left(1-t_{i}\right) w_{i}^{*}\left(t_{i}, t_{j}\right) l_{i}^{*}\left(t_{i}, t_{j}\right)+\pi_{i}^{*}\left(t_{i}, t_{j}\right)-T_{i}$, respectively. The equilibrium in member state $j$ is defined analogously. Finally, we recall that the federal government implements $\phi_{i}^{\prime}=\phi_{j}^{\prime}$ both when the federal fee is proportional to GDP and proportional to GNI.

\subsection{Optimal local policy when the federal fee is proportional to GDP}

When labor is mobile, the consumer's labor supply, $l_{i}^{*}$, may differ from the amount of labor employed by the domestic firm, $L_{i}^{*}$, while the local government, in turn, is restricted to tax labor income at the source. Hence, the local tax base for labor is $w_{i}^{*} L_{i}^{*}$. Since the federal fee is proportional to $\mathrm{GDP}_{i}^{*}=F_{i}\left(L_{i}^{*}\right)$, government $i$ 's maximization problem can be stated as follows:

$$
\max _{t_{i}, T_{i}} u\left[c_{i}^{*}\left(t_{i}, t_{j}, T_{i}\right), h-l_{i}^{*}\left(t_{i}, t_{j}\right)\right]+\phi\left(g_{i}\right)
$$

subject to

$$
g_{i}=T_{i}+t_{i} w_{i}^{*}\left(t_{i}, t_{j}\right) L_{i}^{*}\left(t_{i}, t_{j}\right)-s_{i} F_{i}\left[L_{i}^{*}\left(t_{i}, t_{j}\right)\right]
$$

Government $i$ treats the policy instruments chosen by the other local government $\left(t_{j}\right.$ and $T_{j}$ ) as exogenous. If government $i$ exercises decentralized leadership, then it takes effects via the federal reaction function $s_{i}=s_{i}\left(t_{i}, T_{i}, t_{j}, T_{j}\right)$ into account when choosing $t_{i}$ and $T_{i}$. For the analysis below, we introduce the short notation $a_{i}=-1$ / $\left[w_{i}^{*}\left(\partial L_{i}^{*} / \partial t_{i}\right)\right]>0$ and observe that the after-tax wage, $w_{j}^{n}$, and the tax base for labor in the other state, $I_{j}^{*}$, are determined by:

$$
\begin{aligned}
& w_{j}^{n}\left(t_{i}, t_{j}\right)=\left(1-t_{j}\right) F_{j}^{\prime}\left[L_{j}^{*}\left(t_{i}, t_{j}\right)\right] \\
& I_{j}^{*}\left(t_{i}, t_{j}\right)=F_{j}^{\prime}\left[L_{j}^{*}\left(t_{i}, t_{j}\right)\right] L_{j}^{*}\left(t_{i}, t_{j}\right)
\end{aligned}
$$

Equation (11) implies that the after-tax wage in the other state is decreasing in $t_{i}$, that is

$$
\frac{\partial w_{j}^{n}}{\partial t_{i}}=\left(1-t_{j}\right) F_{j}^{\prime \prime} \frac{\partial L_{j}^{*}}{\partial t_{i}}<0
$$


In the Appendix, we solve the local government's problem and derive the following results;

Proposition 2 Consider an economic federation made up of two member states and a federal government where the latter raises revenue from the local governments via fees that are proportional to each state's GDP, and where labor is mobile between the member states.

(i) In the noncooperative Nash equilibrium, the local government's optimal policy features $\phi_{i}^{\prime} / u_{c}^{i}=1$ and the following (marginal) tax on labor income

$$
t_{i}=a_{i}\left(l_{i}^{*}-L_{i}^{*}\right) \frac{\partial w_{j}^{n}}{\partial t_{i}}+s_{i} .
$$

(ii) Under decentralized leadership, the local government's optimal policy features $\phi_{i}^{\prime} / u_{c}^{i}=2$ and the following (marginal) tax on labor income

$$
t_{i}=a_{i}\left(l_{i}^{*}-L_{i}^{*}\right) \frac{\partial w_{j}^{n}}{\partial t_{i}}+a_{i} t_{j} \frac{\partial I_{j}^{*}}{\partial t_{i}} .
$$

As a point of reference, let us first consider what the outcome would be under cooperation, where a central planner makes all tax and expenditure decisions. This outcome is obtained by solving the same problem as in Sect. 3.1 with the exception that labor is mobile. It can be shown that the solution to this problem will be the same as that outlined in Sect. 3.1, i.e., the central planner implements the first best policy $\phi_{i}^{\prime} / u_{c}^{i}=1$ and $t_{i}=0$.

With this benchmark in mind, let us first interpret the tax policy implemented by the local government in the noncooperative Nash equilibrium. The first term on the right-hand side in Eq. (14) reflects a pecuniary motive to influence the after-tax wage in the other state. This type of motive is well understood from the literature on tax competition (see, e.g., Peralta and van Ypersele 2005; Itaya et al. 2008; Ogawa 2013). In the context of this model, it implies that if state $i$ is a net exporter of labor $\left(l_{i}^{*}>L_{i}^{*}\right)$, then an increase in the after-tax wage in the other state will have a positive effect on the factor income from abroad. This provides government $i$ with an incentive to use tax policy to push up $w_{j}^{n}$. An increase in $w_{j}^{n}$ can be accomplished by subsidizing domestic labor via a reduction in $t_{i}$. This reduces the export of labor to state $j$ which contributes to push up $w_{j}^{n}$. If state $i$ instead is a net importer of labor $\left(l_{i}^{*}<L_{i}^{*}\right)$, then the argument for a higher (marginal) tax rate is analogous. As for the second term on the RHS in Eq. (14), it shows that the proportional fee motive for taxing labor, which is discussed in Sect. 3.2, is present also when labor is mobile.

Turning to the tax policy implemented under decentralized leadership, we begin by recalling that the decentralized leader implements $t_{i}=0$ in the closed economy. Part (ii) in Proposition 2 shows that this result does not hold when labor is mobile. Instead, labor mobility provides the decentralized leader with two distinct motives for implementing a nonzero tax on labor. The first is the pecuniary motive which was discussed in the previous paragraph, while the second is to use $t_{i}$ to influence the size of the tax base for labor in the other state; $I_{j}^{*}\left(t_{i}, t_{j}\right)=w_{j}^{*}\left(t_{i}, t_{j}\right) L_{j}^{*}\left(t_{i}, t_{j}\right)$. 
The reason is that an increase in $I_{j}^{*}$ leads to more tax revenue in state $j$ (as long as $t_{j}>0$ ) which, ceteris paribus, provides the federal government with an incentive to redistribute resources from state $j$ to state $i$ via a lower federal tax rate $s_{i}$. Since this effect works via the federal reaction function, it will only appear when the local government is able to exercise decentralized leadership. We will therefore refer to this as the decentralized leadership motive behind labor income taxation. If $\partial I_{j}^{*} / \partial t_{i}>0$ $\left(\partial I_{j}^{*} / \partial t_{i}<0\right)$, the decentralized leadership motive provides the local government with an incentive to set $t_{i}$ higher (lower) than otherwise. The sign of $\partial I_{j}^{*} / \partial t_{i}$ is determined by:

$$
\operatorname{sign} \frac{\partial I_{j}^{*}}{\partial t_{i}}=\operatorname{sign}\left(1+\frac{1}{\varepsilon_{j}^{d}}\right)
$$

where $\varepsilon_{j}^{d}=\left(\mathrm{d} L_{j}^{d} / \mathrm{d} w_{j}\right) w_{j} / L_{j}<0$ is the elasticity of labor demand. ${ }^{17}$ Equation (16) implies:

Corollary 1 If the local government in state i exercises decentralized leadership, then the decentralized leadership motive provides the local government with an incentive to implement a higher (lower) tax on labor if the labor demand elasticity in the other state exceeds (falls short of) one in absolute value.

Since the federal revenue mechanism in this paper resembles a formulaic transfer scheme, let us briefly relate the results derived above to the literature on incentive effects of formulaic transfer schemes. Smart (1998) analyzes how tax base equalization schemes distort the tax decisions of local governments. He shows that the formulaic transfer mechanism provides an upward pressure on the labor tax, which therefore becomes inefficiently high. Köthenbürger (2002), in turn, analyzes how a federal transfer mechanism affects the taxation of capital in a model with tax competition. Also, he concludes that the federal transfer mechanism has an upward pressure on the tax but since tax competition in itself leads to an inefficiently low taxation of capital, the upward pressure implied by the federal transfer mechanism tends to improve efficiency.

Whether the proportional fee motive addressed in this paper implies that the taxation of labor becomes more or less efficient is ambiguous. Recall that the most efficient tax policy (given that the government has access to a lump-sum instrument) involves setting $t_{i}=0$. In the noncooperative Nash equilibrium, the proportional fee motive induces the local government to implement a higher tax on labor when $s_{i}>0$. Whether

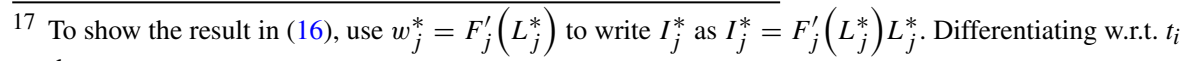
produces

$$
\frac{\partial I_{j}^{*}}{\partial t_{i}}=\left(L_{j}^{*} F_{j}^{\prime \prime}+F_{j}^{\prime}\right) \frac{\partial L_{j}^{*}}{\partial t_{i}}=\left(1+\frac{F_{j}^{\prime}}{L_{j}^{*} F_{j}^{\prime \prime}}\right) L_{j}^{*} F_{j}^{\prime \prime} \frac{\partial L_{j}^{*}}{\partial t_{i}}=\left(1+\varepsilon_{j}^{d}\right) L_{j}^{*} F_{j}^{\prime \prime} \frac{\partial L_{j}^{*}}{\partial t_{i}}=\left(1+\frac{1}{\varepsilon_{j}^{d}}\right) \varepsilon_{j}^{d} L_{j}^{*} F_{j}^{\prime \prime} \frac{\partial L_{j}^{*}}{\partial t_{i}}
$$

where we have used that $\mathrm{d} L_{j}^{d} / \mathrm{d} w_{j}=1 / F_{j}^{\prime \prime}$. Since $\varepsilon_{j}^{d}, F_{j}^{\prime \prime}<0$ and $\partial L_{j}^{*} / \partial t_{i}>0$, it follows that the sign of $\partial I_{j}^{*} / \partial t_{i}$ is determined by the sign of $\left(1+1 / \varepsilon_{j}^{d}\right)$. 
this improves or reduces efficiency depends on whether the pecuniary motive [the first term in Eq. (14)] is negative or positive. Recall that if state $i$ is a net exporter of labor, then the pecuniary motive provides government $i$ with an incentive to implement a lower tax on labor. In this case, the proportional fee motive may lead to more efficiency since it provides government $i$ with an incentive to implement a higher tax. If state $i$ instead is a net exporter of labor (in which case the pecuniary motive provides government $i$ with an incentive to implement a higher tax on labor), then the proportional fee motive exacerbates the inefficiency.

Also when the local government exercises decentralized leadership, the conclusion w.r.t. efficiency is unclear. If the two terms on the RHS of Eq. (15) have the same sign (which happens either if ${ }^{18} l_{i}^{*}<L_{i}^{*}$ and $\left|\varepsilon_{j}^{d}\right|>1$, or if $l_{i}^{*}>L_{i}^{*}$ and $\left|\varepsilon_{j}^{d}\right|<1$ ), then the decentralized leadership motive leads to a more inefficient taxation of labor. The opposite argument applies if, instead, the two terms on the RHS of Eq. (15) have opposite signs (which happens either if $l_{i}^{*}<L_{i}^{*}$ and $\left|\varepsilon_{j}^{d}\right|<1$, or if $l_{i}^{*}>L_{i}^{*}$ and $\left.\left|\varepsilon_{j}^{d}\right|>1\right)$.

Finally, recall that the analysis in this paper is based on the assumption that the federal spending is fixed at an exogenous level $\bar{G}$. What would happen if we were to relax this assumption and instead let $G$ be determined optimally by the federal government? For example, $G$ could be a federal public good. Would the recognition that the size of the federal public good is endogenous influence the incentives underlying the policy implemented by a local government, which exercises decentralized leadership? The answer is no. The reason is that the decentralized leadership motive discussed above implies that government $i$ in the present model already tries to max out the other states' contribution to the federal budget. Making federal expenditure endogenous will not change this conclusion.

\subsubsection{Distortionary taxation}

The analysis conducted above is based on the assumption that the local governments have access to a lump-sum instrument. In this part, we relax this assumption and characterize the outcome when each local government is restricted to only using the distortionary tax on labor to finance its expenditure. Define $\varepsilon_{i}^{w}=\left(\mathrm{d} w_{i}^{*} / \mathrm{d} t_{i}\right) t_{i} / w_{i}^{*}<0$ to be the elasticity of $w_{i}^{*}$ w.r.t. $t_{i}$. In the Appendix, we show that the solution to this optimal tax problem can be summarized as follows:

Corollary 2 When each local government is restricted to only use the distortionary tax on labor to raise revenue, then the optimal policy features the following taxes on labor income.

(i) In a noncooperative Nash equilibrium, the proportional federal revenue system induces government $i$ to implement the following tax on labor income

$$
t_{i}=\left(1+\varepsilon_{i}^{w}\right)\left(\frac{1}{\phi_{i}^{\prime} / u_{c}^{i}}-1\right) \frac{L_{i}^{*}}{\partial L_{i}^{*} / \partial t_{i}}+\frac{a_{i}}{\phi_{i}^{\prime} / u_{c}^{i}}\left(l_{i}^{*}-L_{i}^{*}\right) \frac{\partial w_{j}^{n}}{\partial t_{i}}+s_{i}
$$

18 Conditional on that $t_{j}>0$. 
(ii) If the local government in member state $i$ is able to exercise decentralized leadership, then government $i$ implements the following tax on labor income

$$
t_{i}=\left(1+\varepsilon_{i}^{w}\right)\left(\frac{2}{\phi_{i}^{\prime} / u_{c}^{i}}-1\right) \frac{L_{i}^{*}}{\partial L_{i}^{*} / \partial t_{i}}+\frac{2 a_{i}}{\phi_{i}^{\prime} / u_{c}^{i}}\left(l_{i}^{*}-L_{i}^{*}\right) \frac{\partial w_{j}^{n}}{\partial t_{i}}+a_{i} t_{j} \frac{\partial I_{j}}{\partial t_{i}}
$$

Let us begin with the noncooperative Nash equilibrium. The first term on the RHS of Eq. (17) reflects that the local government is restricted to use the distortionary tax on labor to raise revenue. In this situation, the marginal cost of public funds (reflected by the ratio $\phi_{i}^{\prime} / u_{c}^{i}$ ) is larger than one. ${ }^{19}$ Since both $\varepsilon_{i}^{w}$ and $\partial L_{i}^{*} / \partial t_{i}$ are negative, the first term on the RHS of (17) is positive. The additional two terms that appear on the RHS of Eq. (17) reflect the pecuniary and the proportional fee motives for taxing labor that have been discussed above. We therefore conclude that these two motives will influence tax policy in the same way as outlined above also when the lump-sum tax is not available.

The tax formula under decentralized leadership can be interpreted in a similar way. As such, the first term on the RHS of Eq. (18) implies that when the local government is restricted to use the distortionary tax on labor to raise revenue, then the marginal cost of public funds (reflected by the ratio $\phi_{i}^{\prime} / u_{c}^{i}$ ) is larger than two. ${ }^{20}$ Since both $\varepsilon_{i}^{w}$ and $\partial L_{i}^{*} / \partial t_{i}$ are negative, the first term on the RHS of (18) is positive. The additional two terms that appear on the RHS of Eq. (18) reflect the pecuniary and the decentralized leadership motives for taxing labor that have been discussed earlier. Hence, these two motives will influence tax policy under decentralized leadership also when the lump-sum tax is not available.

\subsubsection{Residence-based taxation}

The results summarized in Proposition 2 are based on the assumption that labor income is taxed at source. What would happen if labor income instead would be taxed at the place of residence? To address this question, we reintroduce the lump-sum tax as a policy instrument for the local government and modify the model outlined above as follows: First, with residence-based taxation, the tax base of labor will be given by $\hat{I}_{i}^{*}=w_{i}^{*} l_{i}^{*}$ instead of $I_{i}^{*}=w_{i}^{*} L_{i}^{*}$. Second, the consumer residing in state $i$ will now face the tax rate $t_{i}$ regardless of whether the income is earned at home or abroad. In this context, labor mobility will ensure that it is the before-tax wages that are equalized between the two member states when the labor market is in equilibrium. In all other aspects, the local government solves the same problem as that outlined in (10). If we define $\theta=\left(\partial L_{i}^{*} / \partial t_{i}\right) /\left(\partial l_{i}^{*} / \partial t_{i}\right)$ and $\hat{a}_{i}=-1 /\left[w_{i}^{*}\left(\partial l_{i}^{*} / \partial t_{i}\right)\right]$, the solution to the local government's maximization problem can be summarized as follows:

\section{Corollary 3 Consider optimal policy under residence-based taxation.}

\footnotetext{
19 Recall that when the lump-sum tax is available as an instrument to raise revenue, then the marginal cost of public funds is one; see part (i) in Proposition 2 where $\phi_{i}^{\prime} / u_{c}^{i}=1$.

20 Recall that when the lump-sum tax is available as an instrument to raise revenue, then the marginal cost of public funds is two; see part (ii) in Proposition 2 where $\phi_{i}^{\prime} / u_{c}^{i}=2$.
} 
(i) In the noncooperative Nash equilibrium, the local government's optimal policy features $\phi_{i}^{\prime} / u_{c}^{i}=1$ and the following (marginal) tax on labor income

$$
t_{i}=\hat{a}_{i}\left(l_{i}^{*}-L_{i}^{*}\right) \frac{\partial w_{j}^{*}}{\partial t_{i}}+\theta s_{i} .
$$

(ii) Under decentralized leadership, the local government's optimal policy features $\phi_{i}^{\prime} / u_{c}^{i}=2$ and the following (marginal) tax on labor income

$$
t_{i}=\hat{a}_{i}\left(l_{i}^{*}-L_{i}^{*}\right) \frac{\partial w_{j}^{*}}{\partial t_{i}}+\hat{a}_{i} t_{j} \frac{\partial \hat{I}_{j}^{*}}{\partial t_{i}} .
$$

A comparison between, on the one hand, Eqs. (14) and (15), and on the other hand, Eqs. (19) and (20), shows that the tax formulas basically take the same form under residence-based taxation as under source-based taxation. The reason is that when lump-sum taxes are available as sources of revenue at the local level, then there is no tax competition motive underlying the taxation of the mobile tax base. Therefore, the remaining motives for taxing labor will be the same in both tax regimes. The first term on the RHS of Eqs. (19) and (20) reflects the pecuniary motive and is analogous to its counterpart under source-based taxation [the first term on the RHS of Eqs. (14) and (15)]. The second term on the RHS of Eq. (19) reflects the proportional fee motive and is analogous to the corresponding term in Eq. (14). The second term on the RHS of Eq. (20), in turn, reflects the decentralized leadership motive and is analogous to the corresponding term in Eq. (15).

There are, however, some minor differences between the equations in Proposition 2 and the equations in Corollary 3. One is that the scaling term that appears in the tax formulas ( $a_{i}$ under source-based taxation and $\hat{a}_{i}$ under residence-based taxation) differs between the two tax regimes. Another is that the second term on the RHS of Eq. (19) is scaled by $\theta=\left(\partial L_{i}^{*} / \partial t_{i}\right) /\left(\partial l_{i}^{*} / \partial t_{i}\right)$, whereas this scaling does not appear in the corresponding tax formula in Proposition 2 [Eq. (14)]. Both these differences reflect that the tax base differs between source-based taxation $\left(I_{i}^{*}=w_{i}^{*} L_{i}^{*}\right)$ and residence-based taxation $\left(\hat{I}_{i}^{*}=w_{i}^{*} l_{i}^{*}\right)$. As a consequence, the distortionary effect of an increase in $t_{i}$ (as measured by the change in the quantity of labor) may differ between the two regimes, i.e., $\partial l_{i}^{*} / \partial t_{i}$ may differ from $\partial L_{i}^{*} / \partial t_{i}$. The larger (in absolute value) that $\partial l_{i}^{*} / \partial t_{i}$ is in comparison with $\partial L_{i}^{*} / \partial t_{i}$, the more distortionary is the tax on labor under residence-based taxation and the lower will $t_{i}$ be set in this scenario. This is captured by the terms $\hat{a}_{i}$ and $\theta$, which are both decreasing in the absolute value of $\partial l_{i}^{*} / \partial t_{i}$. Lower levels of $\hat{a}_{i}$ and $\theta$, in turn, imply a lower $t_{i}$.

\subsection{Optimal local policy when the federal fee is proportional to GNI}

Let us now turn to the problem facing the local government when the federal fee is proportional to GNI. In this scenario, the local government's problem is the same as that outlined in Sect. 4.1 with the exception that the local government's budget constraint is given by $g_{i}=T_{i}+t_{i} w_{i}^{*} L_{i}^{*}-s_{i} \mathrm{GNI}_{i}^{*}$, where $\mathrm{GNI}_{i}^{*}=F_{i}\left(L_{i}^{*}\right)+\mathrm{FI}_{i}^{*}$ and 
$\mathrm{FI}_{i}^{*}=w_{j}^{n}\left(l_{i}^{*}-L_{i}^{*}\right)$. The solution is presented in the Appendix, where the following results are derived:

Proposition 3 Consider an economic federation made up of two member states and a federal government where the latter raises revenue from the local governments via fees that are proportional to each state's GNI, and where labor is mobile between the member states.

(i) In the noncooperative Nash equilibrium, the local government's optimal policy features $\phi_{i}^{\prime} / u_{c}^{i}=1$ and the following (marginal) tax on labor income

$$
t_{i}=a_{i}\left(l_{i}^{*}-L_{i}^{*}\right) \frac{\partial w_{i}^{*}}{\partial t_{i}}+s_{i}-s_{i} a_{i} \frac{\partial F I_{i}^{*}}{\partial t_{i}} .
$$

(ii) Under decentralized leadership, the local government's optimal policy features $\phi_{i}^{\prime} / u_{c}^{i}=2$ and the following (marginal) tax on labor income

$$
t_{i}=a_{i}\left(l_{i}^{*}-L_{i}^{*}\right) \frac{\partial w_{i}^{*}}{\partial t_{i}}+a_{i} t_{j} \frac{\partial I_{j}^{*}}{\partial t_{i}} .
$$

Beginning with part (i), we see that the first two terms on the RHS of Eq. (21) are identical to, and can be interpreted in a similar way, as the terms that appear on the RHS of Eq. (14). The novelty is the appearance of the third term on the RHS of Eq. (21). It appears as a direct consequence of the fact that the federal fee is proportional to GNI instead of GDP. To explain why this term appears, let us conduct the same thought experiment as we used to interpret Proposition 1. Therefore, assume that the local government initially has made an optimal choice of $T_{i}$ conditional on that $t_{i}$ is zero. Then we ask whether the local government has an incentive to change $t_{i}$ from zero? Differentiating the local government's objective function w.r.t. $t_{i}$, evaluating the resulting expression at $t_{i}=0$ and using that the optimal choice of $T_{i}$ satisfies $\phi_{i}^{\prime} / u_{c}^{i}=1$ produce $^{21}$

$$
\left.\frac{\partial U_{i}}{\partial t_{i}}\right|_{t_{i}=0}=\phi_{i}^{\prime}\left(l_{i}^{*}-L_{i}^{*}\right) \frac{\partial w_{j}^{n}}{\partial t_{i}}-\phi_{i}^{\prime} s_{i} \frac{\partial \mathrm{GNI}_{i}^{*}}{\partial t_{i}}
$$

where

$$
\frac{\partial \mathrm{GNI}_{i}^{*}}{\partial t_{i}}=w_{i}^{*} \frac{\partial L_{i}^{*}}{\partial t_{i}}+\frac{\partial \mathrm{FI}_{i}^{*}}{\partial t_{i}}
$$

Substituting Eq. (24) into Eq. (23) produces

$$
\left.\frac{\partial U_{i}}{\partial t_{i}}\right|_{t_{i}=0}=\phi_{i}^{\prime}\left(l_{i}^{*}-L_{i}^{*}\right) \frac{\partial w_{j}^{n}}{\partial t_{i}}-\phi_{i}^{\prime} s_{i} w_{i}^{*} \frac{\partial L_{i}^{*}}{\partial t_{i}}-\phi_{i}^{\prime} s_{i} \frac{\partial \mathrm{FI}_{i}^{*}}{\partial t_{i}}
$$

\footnotetext{
${ }^{21}$ Equation (23) is obtained by differentiating Eq. (A18) in the Appendix, w.r.t. $t_{i}$. To simplify the resulting expression for $\partial U_{i} / \partial t_{i}$, we use $\phi_{i}^{\prime} / u_{c}^{i}=1, t_{i}=0, \partial s_{i} / \partial t_{i}=0$ and Eq. (A12) in the Appendix.
} 
The first and second terms on the RHS of Eq. (25) reflect the pecuniary and the proportional fee motives for taxing labor. The novelty is the appearance of the third term on the RHS which reflects that the federal tax base is broader when it is based on $\mathrm{GNI}_{i}^{*}=\mathrm{GDP}_{i}^{*}+\mathrm{FI}_{i}^{*}$ instead of $\mathrm{GDP}_{i}^{*}$. This implies that the local government in member state $i$ needs to take effects via $\mathrm{FI}_{i}^{*}$ into account (in addition to effects via GDP ${ }_{i}^{*}$ ) when evaluating how $t_{i}$ can be used to reduce the size of the fee paid to the federal level. From this perspective, the third term on the RHS of Eq. (25) reflects an extended proportional fee motive for taxing labor that arises when the federal fee is proportional to GNI. Since the payment to the federal level (all else equal) increases with $\mathrm{FI}_{i}$, government $i$ has a motive to reduce $\mathrm{FI}_{i}$. Therefore, if $\partial \mathrm{FI}_{i} / \partial t_{i}>0\left(\partial \mathrm{FI}_{i} / \partial t_{i}<0\right)$, the local government has an incentive to set $t_{i}$ lower (higher) than otherwise. This is captured by the third term on the RHS of Eq. (25), and this motive is also reflected by the third term on the RHS of the tax formula in Eq. (21). By using the comparative static properties of the functions that make up $\mathrm{FI}_{i}=w_{j}^{n}$ $\left(l_{i}^{*}-L_{i}^{*}\right)$, it is possible to rewrite Eq. (21) to read (see "Appendix")

$$
t_{i}=a_{i}\left(l_{i}^{*}-L_{i}^{*}\right) \frac{\partial w_{j}^{n}}{\partial t_{i}}-a_{i} \frac{s_{i}}{1-s_{i}} w_{j}^{n} \frac{\partial w_{j}^{n}}{\partial t_{i}} \frac{\partial l_{i}^{*}}{\partial w_{i}^{n}}
$$

where we have used that the identity $w_{i}^{n}=w_{j}^{n}$ implies that $l_{i}^{*}\left(t_{i}, t_{j}\right)=l_{i}^{*}\left[w_{j}^{n}\left(t_{i}, t_{j}\right)\right]$. Hence,

$$
\frac{\partial l_{i}^{*}}{\partial t_{i}}=\frac{\partial l_{i}^{*}}{\partial w_{i}^{n}} \frac{\partial w_{j}^{n}}{\partial t_{i}}
$$

Since $a_{i}$ and $\partial l_{i} / \partial w_{i}^{n}$ are both positive while $\partial w_{j}^{n} / \partial t_{i}$ is negative, the second term on the RHS of $\left(21^{\prime}\right)$ is positive (including the minus sign). Since the first term on the RHS of $\left(21^{\prime}\right)$ reflects the pecuniary motive, the following result is readily available:

Corollary 4 If state $i$ is a net contributor of funds to the federal government $\left(s_{i}>\right.$ 0 ), then the (marginal) tax on labor income exceeds the pecuniary motive in the noncooperative Nash equilibrium; $t_{i}>a_{i}\left(l_{i}^{*}-L_{i}^{*}\right) \partial w_{j}^{n} / \partial t_{i}$.

Turning to part (ii) in Proposition 3, we see that Eq. (22) is identical to Eq. (15). We therefore conclude that the incentive structure underlying the optimal (marginal) labor income tax implemented by a decentralized leader is independent of whether the federal government uses fees that are proportional to GDP or GNI, to collect its revenue.

\subsection{No federal redistribution}

The analysis above is based on the assumption that the federal government, in addition to financing the exogenous expenditure $\bar{G}$, has an incentive to achieve redistribution between the two member states. Let us now relax the latter assumption and characterize the outcome when the federal government has no distributional motive and is 
only concerned with raising funds to finance the expenditure $\bar{G}$. To do this, we first observe that when redistribution is no longer a concern for the federal government, then there is no motive for having a differentiated federal tax rate. Therefore, the federal government levies the same federal tax rate, $s$, on both state $i$ and state $j$. If the federal fee is proportional to GDP, then the federal budget constraint becomes $\bar{G}=s\left(\mathrm{GDP}_{i}^{*}+\mathrm{GDP}_{j}^{*}\right)$, but if the federal fee instead is proportional to GNI, then the federal budget constraint is given by $\bar{G}=s\left(\mathrm{GNI}_{i}^{*}+\mathrm{GNI}_{j}^{*}\right)$. Since the factor incomes sum to zero over the two member states, it follows that $\mathrm{FI}_{i}^{*}=-\mathrm{FI}_{j}^{*}$ and $\mathrm{GDP}_{i}^{*}+\mathrm{GDP}_{j}^{*}=\mathrm{GNI}_{i}^{*}+\mathrm{GNI}_{j}^{*}$. This implies that the federal reaction function in either case is given by $s=\bar{G} /\left(\mathrm{GDP}_{i}^{*}+\mathrm{GDP}_{j}^{*}\right)$. In the Appendix, we solve the decentralized leader's problem when the federal fee is proportional to GDP and derive the following results:

Proposition 4 Consider an economic federation made up of two member states and a federal government where the latter levies the same proportional federal tax rate, $s$, on both member states. When labor is mobile and the federal fee is proportional to GDP, the decentralized leader implements the following (marginal tax) on labor income

$$
t_{i}=a_{i}\left(l_{i}^{*}-L_{i}^{*}\right) \frac{\partial w_{j}^{n}}{\partial t_{i}}+s \frac{Y_{j}^{*}}{Y_{i}^{*}+Y_{j}^{*}}+a_{i} s \frac{Y_{i}^{*}}{Y_{i}^{*}+Y_{j}^{*}} w_{j}^{*} \frac{\partial L_{j}^{*}}{\partial t_{i}}
$$

The first term on the RHS reflects the pecuniary motive, while the second term reflects the proportional fee motive, for taxing labor. Recall from the analysis conducted earlier that when the federal government can implement state-specific federal taxes $\left(s_{i}\right)$, then the proportional fee motive for taxing labor at the local level vanishes when the local government can exercise decentralized leadership. The reason was that the federal government responds to the proportional fee motive by increasing the state-specific federal tax rate $s_{i}$ so as to balance out the negative impact on the federal tax base. However, when the federal government applies the same federal tax rate $s$ on all member states, the federal response to something that happens in member state $i$ will be imperfect. This means that a part of the proportional fee motive for taxing labor will remain for the decentralized leader in this scenario. This is captured by the term $s Y_{j}^{*} /\left(Y_{i}^{*}+Y_{j}^{*}\right)$ which appears on the RHS in Eq. (27).

As for the final term on the RHS of Eq. (27), it is analogous to the decentralized leadership motive that arises in Eqs. (15) and (22). To see this, recall that the decentralized leadership motive arises because government $i$ has an incentive to increase the tax base in state $j$, since this induces the federal government to reduce the federal tax rate imposed on state $i$. Also when the federal budget constraint is given by $\bar{G}=s$ $\left(\mathrm{GDP}_{i}^{*}+\mathrm{GDP}_{j}^{*}\right)$, an increase in state $j$ 's GDP will allow the federal government to reduce $s$. Since $\mathrm{GDP}_{j}^{*}=F_{j}\left[L_{j}\left(t_{i}, t_{j}\right)\right]$ and $\partial L_{j}^{*} / \partial t_{i}>0$, it follows that an increase 
in $t_{i}$ will have a positive effect on state $j$ 's GDP. This provides government $i$ with an incentive to set $t_{i}$ higher than otherwise, and is captured by the final term on the RHS of Eq. (27) which is positive.

\section{Conclusions}

This paper concerns optimal taxation of labor in an economic federation where the federal level uses membership fees that are proportional either to GDP or to GNI to raise revenue from the lower-level jurisdictions. The paper extends the analyses of previous studies by incorporating proportional membership fees into a framework where one of the lower-level jurisdictions may be able to exert decentralized leadership. I would like to emphasize four broad conclusions:

(i) If the state governments act as Nash followers and are net contributors of funds to the federal level, then a federal revenue mechanism that is proportional to either GDP or GNI will provide the state governments with an incentive to implement a positive (marginal) tax on labor income (via the proportional fee motive discussed in the text). If the federal revenue mechanism is proportional to GNI, then a state government has an additional incentive to implement a higher (lower) labor income tax (compared with when the federal revenue mechanism is proportional to GDP) if the factor income from abroad is a decreasing (increasing) function of the (marginal) tax on labor.

(ii) If the state government exercises decentralized leadership vis-à-vis a federal government which is concerned with income redistribution between the member states, then the (marginal) tax on labor implemented by the state government is independent of whether the federal fee is proportional to GDP or GNI. It was shown that decentralized leadership in itself (the decentralized leadership motive discussed in the text) provides the local government with an incentive to implement a higher (lower) labor income tax if the labor demand elasticity in the other state exceeds (falls short of) one in absolute value.

(iii) If the federal government is not concerned with income redistribution between the member states, then the proportional federal revenue mechanism provides a decentralized leader with an incentive to implement a higher (marginal) tax on labor.

(iv) The incentives underlying the taxation of labor are the same under source-based taxation as under residence-based taxation (as long as lump-sum taxes are available).

The analysis conducted in this paper indicates that the introduction of a proportional EU financing scheme may have provided member countries which act as Nash followers vis-à-vis the upper level in EU with an incentive to tax labor at a higher rate than before (via the proportional fee motive discussed in the text). The analysis also suggests that the introduction of a proportional EU financing scheme may have increased the tax efficiency for member states which are net exporters of labor within the EU, whereas the opposite conclusion holds for member states which are net importers of labor. 
Open Access This article is distributed under the terms of the Creative Commons Attribution 4.0 International License (http://creativecommons.org/licenses/by/4.0/), which permits unrestricted use, distribution, and reproduction in any medium, provided you give appropriate credit to the original author(s) and the source, provide a link to the Creative Commons license, and indicate if changes were made.

\section{Appendix}

\section{Comparative static properties of the functions $L_{i}^{*}\left(t_{i}, t_{j}\right)$ and $L_{j}^{*}\left(t_{i}, t_{j}\right)$}

To determine the comparative static properties of these functions, we differentiate Eqs. (8) and (9) w.r.t. $t_{i}, L_{i}^{*}$, and $L_{j}^{*}$. This produces

$$
\left[\begin{array}{ll}
F_{i}^{\prime \prime}\left(1-t_{i}\right) & -F_{j}^{\prime \prime}\left(1-t_{j}\right) \\
\left(1-\frac{\mathrm{d} l_{i}}{\mathrm{~d} w_{i}^{n}}\left(1-t_{i}\right) F_{i}^{\prime \prime}\right) & \left(1-\frac{\mathrm{d} l_{j}}{\mathrm{~d} w_{j}^{n}}\left(1-t_{j}\right) F_{j}^{\prime \prime}\right)
\end{array}\right] \cdot\left[\begin{array}{l}
\partial L_{i}^{*} / \partial t_{i} \\
\partial L_{j}^{*} / \partial t_{i}
\end{array}\right]=\left[\begin{array}{c}
w_{i} \\
-\frac{\mathrm{d} l_{i}}{\mathrm{~d} w_{i}^{n}} w_{i}
\end{array}\right]
$$

where $w_{i}^{n}=\left(1-t_{i}\right) w_{i}$ and $w_{j}^{n}=\left(1-t_{j}\right) w_{j}$. The determinant of the matrix on the LHS is given by:

$$
\Phi=F_{i}^{\prime \prime}\left(1-t_{i}\right)\left(1-\frac{\mathrm{d} l_{j}}{\mathrm{~d} w_{j}^{n}}\left(1-t_{j}\right) F_{j}^{\prime \prime}\right)+F_{j}^{\prime \prime}\left(1-t_{j}\right)\left(1-\frac{\mathrm{d} l_{i}}{\mathrm{~d} w_{i}^{n}}\left(1-t_{i}\right) F_{i}^{\prime \prime}\right)<0
$$

By using Cramer's rule, we obtain

$$
\frac{\partial L_{i}^{*}}{\partial t_{i}}=\frac{w_{i}\left(1-\frac{\mathrm{d} l_{j}}{\mathrm{~d} w_{j}^{n}}\left(1-t_{j}\right) F_{j}^{\prime \prime}\right)-w_{i} F_{j}^{\prime \prime}\left(1-t_{j}\right) \frac{\mathrm{d} l_{i}}{\mathrm{~d} w_{i}^{n}}}{\Phi}<0, \quad \frac{\partial L_{j}^{*}}{\partial t_{i}}=-\frac{w_{i}}{\Phi}>0
$$

If we instead differentiate Eqs. (8) and (9) w.r.t. $t_{j}, L_{i}^{*}$, and $L_{j}^{*}$, we obtain

$$
\left[\begin{array}{ll}
F_{i}^{\prime \prime}\left(1-t_{i}\right) & -F_{j}^{\prime \prime}\left(1-t_{j}\right) \\
\left(1-\frac{\mathrm{d} l_{i}}{\mathrm{~d} w_{i}^{n}}\left(1-t_{i}\right) F_{i}^{\prime \prime}\right) & \left(1-\frac{\mathrm{d} l_{j}}{\mathrm{~d} w_{j}^{n}}\left(1-t_{j}\right) F_{j}^{\prime \prime}\right)
\end{array}\right] \cdot\left[\begin{array}{l}
\partial L_{i}^{*} / \partial t_{j} \\
\partial L_{j}^{*} / \partial t_{j}
\end{array}\right]=\left[\begin{array}{c}
-w_{j} \\
-\frac{\mathrm{d} l_{j}}{\mathrm{~d} w_{j}^{n}} w_{j}
\end{array}\right]
$$

Again using Cramer's rule produces

$$
\frac{\partial L_{i}^{*}}{\partial t_{j}}=-\frac{w_{j}}{\Phi}>0, \quad \frac{\partial L_{j}^{*}}{\partial t_{j}}=\frac{w_{j}\left(1-\frac{\mathrm{d} l_{i}}{\mathrm{~d} w_{i}^{n}}\left(1-t_{i}\right) F_{i}^{\prime \prime}\right)-w_{j} F_{i}^{\prime \prime}\left(1-t_{i}\right) \frac{\mathrm{d} l_{j}}{\mathrm{~d} w_{j}^{n}}}{\Phi}<0 .
$$




\section{Optimal policy under cooperation: federal fee is proportional to GNI}

The central planner's objective function can be written as follows:

$$
\begin{aligned}
W= & u\left\{\left(1-t_{i}\right) w_{i}^{*}\left(t_{i}, t_{j}\right) l_{i}^{*}\left(t_{i}, t_{j}\right)+F_{i}\left[L_{i}^{*}\left(t_{i}, t_{j}\right)\right]-w_{i}^{*}\left(t_{i}, t_{j}\right) L_{i}^{*}\left(t_{i}, t_{j}\right)-T_{i}, h-l_{i}^{*}\left(t_{i}, t_{j}\right)\right\} \\
& +u\left\{\left(1-t_{j}\right) w_{j}^{*}\left(t_{i}, t_{j}\right) l_{j}^{*}\left(t_{i}, t_{j}\right)+F_{j}\left[L_{j}^{*}\left(t_{i}, t_{j}\right)\right]-w_{j}^{*}\left(t_{i}, t_{j}\right) L_{j}^{*}\left(t_{i}, t_{j}\right)-T_{j}, h-l_{j}^{*}\left(t_{i}, t_{j}\right)\right\} \\
& +\phi\left\{T_{i}+t_{i} w_{i}^{*}\left(t_{i}, t_{j}\right) L_{i}^{*}\left(t_{i}, t_{j}\right)-s_{i} \mathrm{GNI}_{i}\left(t_{i}, t_{j}\right)\right\} \\
& +\phi\left\{T_{j}+t_{j} w_{j}^{*}\left(t_{i}, t_{j}\right) L_{j}^{*}\left(t_{i}, t_{j}\right)+s_{i} \mathrm{GNI}_{i}\left(t_{i}, t_{j}\right)-\bar{G}\right\}
\end{aligned}
$$

By using the private first-order conditions, the first-order conditions become:

$$
\begin{gathered}
\frac{\partial W}{\partial s_{i}}=Y_{i}\left(\phi_{j}^{\prime}-\phi_{i}^{\prime}\right)=0 \\
\frac{\partial W}{\partial T_{i}}=\phi_{i}^{\prime}-u_{c}^{i}=0 \\
\frac{\partial W}{\partial T_{j}}=\phi_{j}^{\prime}-u_{c}^{j}=0
\end{gathered}
$$

$$
\begin{aligned}
\frac{\partial W}{\partial t_{i}}= & \phi_{i}^{\prime}\left(w_{i}^{*} L_{i}^{*}+t_{i} L_{i}^{*} \frac{\partial w_{i}^{*}}{\partial t_{i}}+t_{i} w_{i}^{*} \frac{\partial L_{i}^{*}}{\partial t_{i}}-s_{i} \frac{\partial \mathrm{GNI}_{i}}{\partial t_{i}}\right) \\
& +u_{c}^{i}\left(-w_{i}^{*} l_{i}^{*}+\left(1-t_{i}\right) l_{i}^{*} \frac{\partial w_{i}^{*}}{\partial t_{i}}-L_{i}^{*} \frac{\partial w_{i}^{*}}{\partial t_{i}}\right) \\
& +\phi_{j}^{\prime}\left(t_{j} L_{j}^{*} \frac{\partial w_{j}^{*}}{\partial t_{i}}+t_{j} w_{j}^{*} \frac{\partial L_{j}^{*}}{\partial t_{i}}+s_{i} \frac{\partial \mathrm{GNI}_{i}}{\partial t_{i}}\right)+u_{c}^{j}\left(\left(1-t_{j}\right) l_{j}^{*} \frac{\partial w_{j}^{*}}{\partial t_{i}}-L_{j}^{*} \frac{\partial w_{j}^{*}}{\partial t_{i}}\right) \\
= & 0
\end{aligned}
$$

$$
\begin{aligned}
\frac{\partial W}{\partial t_{j}}= & \phi_{j}^{\prime}\left(w_{j}^{*} L_{j}^{*}+t_{j} L_{j}^{*} \frac{\partial w_{j}^{*}}{\partial t_{j}}+t_{j} w_{j}^{*} \frac{\partial L_{j}^{*}}{\partial t_{j}}+s_{i} \frac{\partial \mathrm{GNI}_{i}}{\partial t_{j}}\right) \\
& +u_{c}^{j}\left(-w_{j}^{*} l_{j}^{*}+\left(1-t_{j}\right) l_{j}^{*} \frac{\partial w_{j}^{*}}{\partial t_{j}}-L_{j}^{*} \frac{\partial w_{j}^{*}}{\partial t_{j}}\right) \\
& +\phi_{i}^{\prime}\left(t_{i} L_{i}^{*} \frac{\partial w_{i}^{*}}{\partial t_{j}}+t_{i} w_{i}^{*} \frac{\partial L_{i}^{*}}{\partial t_{j}}-s_{i} \frac{\partial \mathrm{GNI}_{i}}{\partial t_{j}}\right)+u_{c}^{i}\left(\left(1-t_{i}\right) l_{i}^{*} \frac{\partial w_{i}^{*}}{\partial t_{j}}-L_{i}^{*} \frac{\partial w_{i}^{*}}{\partial t_{j}}\right) \\
= & 0
\end{aligned}
$$


Use that (A6)-(A8) together imply $u_{c}^{i}=\phi_{i}^{\prime}=\phi_{j}^{\prime}=u_{c}^{j}$. This verifies the first and third equations in (4). Using these results in (A9) and collecting terms produce

$$
\left[\left(1-t_{i}\right) \frac{\partial w_{i}^{*}}{\partial t_{i}}-w_{i}^{*}\right]\left(l_{i}^{*}-L_{i}^{*}\right)+\left(1-t_{j}\right) \frac{\partial w_{j}^{*}}{\partial t_{i}}\left(l_{j}^{*}-L_{j}^{*}\right)+t_{i} w_{i}^{*} \frac{\partial L_{i}^{*}}{\partial t_{i}}+t_{j} w_{j}^{*} \frac{\partial L_{j}^{*}}{\partial t_{i}}=0
$$

Use that the identity $w_{j}^{n}=\left(1-t_{j}\right) w_{j}^{*}\left(t_{i}, t_{j}\right)=\left(1-t_{i}\right) w_{i}^{*}\left(t_{i}, t_{j}\right)$ implies

$$
\frac{\partial w_{j}^{n}}{\partial t_{i}}=\left(1-t_{j}\right) \frac{\partial w_{j}^{*}}{\partial t_{i}}=\left(1-t_{i}\right) \frac{\partial w_{i}^{*}}{\partial t_{i}}-w_{i}^{*}
$$

and that $l_{i}^{*}+l_{j}^{*}-L_{i}^{*}-L_{j}^{*}=0$. Then, (A11) reduces to

$$
t_{i} w_{i}^{*} \frac{\partial L_{i}^{*}}{\partial t_{i}}+t_{j} w_{j}^{*} \frac{\partial L_{j}^{*}}{\partial t_{i}}=0
$$

Using an analogous approach to simplify (A10) produces

$$
t_{i} w_{i}^{*} \frac{\partial L_{i}^{*}}{\partial t_{j}}+t_{j} w_{j}^{*} \frac{\partial L_{j}^{*}}{\partial t_{j}}=0
$$

Equations (A13) and (A14) are satisfied when $t_{i}=0$ and $t_{j}=0$. This verifies the second equation in (4). By using this approach, it can be verified that the equations in (4) also hold when the federal fee is proportional to GDP and when labor is immobile.

\section{Optimal policy with separate federal and local governments: federal fee is proportional to GNI}

Since the outcomes when the federal fee is proportional to GDP, and when labor is immobile, are special cases of the outcome when the federal fee is proportional to GNI and labor is mobile, we here present the solution in the latter scenario. The federal government's objective function can be written as follows:

$$
\begin{aligned}
W= & \phi\left\{T_{i}+t_{i} w_{i}^{*}\left(t_{i}, t_{j}\right) L_{i}^{*}\left(t_{i}, t_{j}\right)-s_{i} \mathrm{GNI}_{i}\left(t_{i}, t_{j}\right)\right\} \\
& +\phi\left\{T_{j}+t_{j} w_{j}^{*}\left(t_{i}, t_{j}\right) L_{j}^{*}\left(t_{i}, t_{j}\right)+s_{i} \mathrm{GNI}_{i}\left(t_{i}, t_{j}\right)-\bar{G}\right\}
\end{aligned}
$$

The first-order condition w.r.t. $s_{i}$ becomes

$$
\frac{\mathrm{d} W}{\mathrm{~d} s_{i}}=Y_{i}\left(\phi_{j}^{\prime}-\phi_{i}^{\prime}\right)=0
$$


(A15) implies $\phi_{i}^{\prime}=\phi_{j}^{\prime}$ which, in turn, implies that $\phi_{i}^{\prime \prime}=\phi_{j}^{\prime \prime}$. By differentiating (A15) w.r.t. $s_{i}, t_{i}$ and $T_{i}$, we can derive the following comparative static properties for the federal reaction function

$$
\begin{gathered}
\frac{\partial s_{i}}{\partial T_{i}}=\frac{1}{\mathrm{GNI}_{i}} \frac{\phi_{i}^{\prime \prime}}{\phi_{i}^{\prime \prime}+\phi_{j}^{\prime \prime}} \\
\frac{\partial s_{i}}{\partial t_{i}}=\frac{\phi_{i}^{\prime \prime}\left(w_{i}^{*} L_{i}^{*}+t_{i} L_{i}^{*} \frac{\partial w_{i}^{*}}{\partial t_{i}}+t_{i} w_{i}^{*} \frac{\partial L_{i}^{*}}{\partial t_{i}}-s_{i} \frac{\partial \mathrm{GNI}_{i}}{\partial t_{i}}\right)-\phi_{j}^{\prime \prime}\left(t_{j} L_{j}^{*} \frac{\partial w_{j}^{*}}{\partial t_{i}}+t_{j} w_{j}^{*} \frac{\partial L_{j}^{*}}{\partial t_{i}}+s_{i} \frac{\partial \mathrm{GNI}_{i}}{\partial t_{i}}\right)}{\mathrm{GNI}_{i}\left(\phi_{i}^{\prime \prime}+\phi_{j}^{\prime \prime}\right)}
\end{gathered}
$$

The local government's objective function can be written as:

$$
\begin{aligned}
U_{i}= & u\left\{\left(1-t_{i}\right) w_{i}^{*}\left(t_{i}, t_{j}\right) l_{i}^{*}\left(t_{i}, t_{j}\right)+F_{i}\left[L_{i}^{*}\left(t_{i}, t_{j}\right)\right]-w_{i}^{*}\left(t_{i}, t_{j}\right) L_{i}^{*}\left(t_{i}, t_{j}\right)-T_{i}, h-l_{i}^{*}\left(t_{i}, t_{j}\right)\right\} \\
& +\phi\left\{T_{i}+t_{i} w_{i}^{*}\left(t_{i}, t_{j}\right) L_{i}^{*}\left(t_{i}, t_{j}\right)-s_{i} \mathrm{GNI}_{i}\left(t_{i}, t_{j}\right)\right\}
\end{aligned}
$$

The first-order conditions become (where we have used the private first-order condition for labor to simplify)

$$
\begin{gathered}
0=\phi_{i}^{\prime}-u_{c}^{i}-\phi_{i}^{\prime} \mathrm{GNI}_{i} \frac{\partial s_{i}}{\partial T_{i}} \\
0=\phi_{i}^{\prime}\left(w_{i}^{*} L_{i}^{*}+t_{i} L_{i}^{*} \frac{\partial w_{i}^{*}}{\partial t_{i}}+t_{i} w_{i}^{*} \frac{\partial L_{i}^{*}}{\partial t_{i}}-s_{i} \frac{\partial \mathrm{GNI}_{i}}{\partial t_{i}}-\mathrm{GNI}_{i} \frac{\partial s_{i}}{\partial t_{i}}\right) \\
+u_{c}^{i}\left(\left(1-t_{i}\right) l_{i}^{*} \frac{\partial w_{i}^{*}}{\partial t_{i}}-L_{i}^{*} \frac{\partial w_{i}^{*}}{\partial t_{i}}-w_{i}^{*} l_{i}^{*}\right)
\end{gathered}
$$

Consider first the noncooperative Nash equilibrium, where $s_{i}$ is treated as exogenous by government $i$, i.e., $\partial s_{i} / \partial T_{i}=\partial s_{i} / \partial t_{i}=0$. Using that (A19) implies $\phi_{i}^{\prime} / u_{c}^{i}=1$ in (A20) and rearranging produce

$$
t_{i} w_{i}^{*} \frac{\partial L_{i}^{*}}{\partial t_{i}}-s_{i} \frac{\partial \mathrm{GNI}_{i}}{\partial t_{i}}+\left[\left(1-t_{i}\right) \frac{\partial w_{i}^{*}}{\partial t_{i}}-w_{i}^{*}\right]\left(l_{i}^{*}-L_{i}^{*}\right)=0
$$

Use that $\mathrm{GNI}_{i}=F_{i}\left(L_{i}^{*}\right)+$ FI implies

$$
\frac{\partial \mathrm{GNI}_{i}}{\partial t_{i}}=w_{i}^{*} \frac{\partial L_{i}^{*}}{\partial t_{i}}+\frac{\partial \mathrm{FI}_{i}}{\partial t_{i}}
$$

Substituting (A22) into (A21), using (A12) and solving for $t_{i}$ produce

$$
t_{i}=a_{i}\left(l_{i}^{*}-L_{i}^{*}\right) \frac{\partial w_{j}^{n}}{\partial t_{i}}+s_{i}-s_{i} a_{i} \frac{\partial \mathrm{FI}_{i}}{\partial t_{i}}
$$


This is Eq. (21) in Proposition 3. Since $\mathrm{FI}_{i}=w_{j}^{n}\left(l_{i}^{*}-L_{i}^{*}\right)$, it follows that

$$
\frac{\partial \mathrm{FI}_{i}}{\partial t_{i}}=\left(l_{i}^{*}-L_{i}^{*}\right) \frac{\partial w_{j}^{n}}{\partial t_{i}}+w_{j}^{n}\left(\frac{\partial l_{i}^{*}}{\partial t_{i}}-\frac{\partial L_{i}^{*}}{\partial t_{i}}\right)
$$

Substituting (26), (A24) and $w_{j}^{n}=\left(1-t_{i}\right) w_{i}^{*}$ into (A23), and solving again for $t_{i}$ produce Eq. $\left(21^{\prime}\right)$ in the text. Furthermore, we note that when $\mathrm{FI}_{i}$ is redundant, then (A23) reduces to Eq. (14) in Proposition 2. In addition, when $l_{i}^{*}=L_{i}^{*}$, then Eq. (14) in the text reduces to $t_{i}=s_{i}$ which is the tax policy outlined in part (i) in Proposition 1. Finally, we note that (A19) implies that $\phi_{i}^{\prime} / u_{c}^{i}=1$ holds in all scenarios in the noncooperative Nash equilibrium.

Turning to the decentralized leader, multiply (A19) by $w_{i}^{*} l_{i}^{*}$, subtract the resulting expression from (A20) and divide by $u_{c}^{i}$. This produces

$$
\begin{aligned}
0= & \frac{\phi_{i}^{\prime}}{u_{c}^{i}}\left(w_{i}^{*} L_{i}^{*}-w_{i}^{*} l_{i}^{*}+t_{i} L_{i}^{*} \frac{\partial w_{i}^{*}}{\partial t_{i}}+t_{i} w_{i}^{*} \frac{\partial L_{i}^{*}}{\partial t_{i}}-s_{i} \frac{\partial \mathrm{GNI}_{i}}{\partial t_{i}}\right) \\
& +\left(1-t_{i}\right) l_{i}^{*} \frac{\partial w_{i}^{*}}{\partial t_{i}}-L_{i}^{*} \frac{\partial w_{i}^{*}}{\partial t_{i}}-\frac{\phi_{i}^{\prime}}{u_{c}^{i}} \mathrm{GNI}_{i}\left(\frac{\partial s_{i}}{\partial t_{i}}-w_{i}^{*} l_{i}^{*} \frac{\partial s_{i}}{\partial T_{i}}\right)
\end{aligned}
$$

Let us evaluate the expression inside the last pair of brackets by using (A16) and (A17)

$$
\begin{aligned}
\frac{\partial s_{i}}{\partial t_{i}}-w_{i}^{*} l_{i}^{*} \frac{\partial s_{i}}{\partial T_{i}} & \phi_{i}^{\prime \prime}\left(w_{i}^{*} L_{i}^{*}-w_{i}^{*} l_{i}^{*}+t_{i} L_{i}^{*} \frac{\partial w_{i}^{*}}{\partial t_{i}}+t_{i} w_{i}^{*} \frac{\partial L_{i}^{*}}{\partial t_{i}}-s_{i} \frac{\partial \mathrm{GNI}_{i}}{\partial t_{i}}\right)-\phi_{j}^{\prime \prime}\left(t_{j} L_{j}^{*} \frac{\partial w_{j}^{*}}{\partial t_{i}}+t_{j} w_{j}^{*} \frac{\partial L_{j}^{*}}{\partial t_{i}}+s_{i} \frac{\partial \mathrm{GNI}_{i}}{\partial t_{i}}\right) \\
= & \mathrm{GNI}_{i}\left(\phi_{i}^{\prime \prime}+\phi_{j}^{\prime \prime}\right)
\end{aligned}
$$

Also substitute (A16) into (A19) and rearrange

$$
\frac{\phi_{i}^{\prime}}{u_{c}^{i}}=\frac{\phi_{i}^{\prime \prime}+\phi_{j}^{\prime \prime}}{\phi_{j}^{\prime \prime}}=2
$$

Substitute (A26) into (A25). Multiply by $\left(\phi_{i}^{\prime \prime}+\phi_{j}^{\prime \prime}\right)$, use (A27) to eliminate common terms and divide the resulting expression by $\phi_{i}^{\prime \prime} \phi_{j}^{\prime} / u_{c}^{i}$. Rearranging the resulting expression produces

$$
0=\left[\left(1-t_{i}\right) \frac{\partial w_{i}^{*}}{\partial t_{i}}-w_{i}^{*}\right]\left(l_{i}^{*}-L_{i}^{*}\right)+t_{i} w_{i}^{*} \frac{\partial L_{i}^{*}}{\partial t_{i}}+\left(t_{j} L_{j}^{*} \frac{\partial w_{j}^{*}}{\partial t_{i}}+t_{j} w_{j}^{*} \frac{\partial L_{j}^{*}}{\partial t_{i}}\right)
$$

Use (A12) to replace the expression inside square brackets by $\partial w_{j}^{n} / \partial t_{i}$. Also use that the definition in (12) implies

$$
\frac{\partial I_{j}^{*}}{\partial t_{i}}=t_{j} L_{j}^{*} \frac{\partial w_{j}^{*}}{\partial t_{i}}+t_{j} w_{j}^{*} \frac{\partial L_{j}^{*}}{\partial t_{i}}
$$


Using this expression to replace the last expression inside brackets in (A28) and then solving for $t_{i}$ produce Eq. (22) in Proposition 3. Using a similar approach when the federal fee is proportional to GDP produces Eq. (15) in the text. Since $l_{i}^{*}=L_{i}^{*}$, and since the tax base in the other state $j$ is not a function of $t_{i}$ when labor is immobile, it follows that the decentralized leader sets $t_{i}=0$ in this scenario, as outlined in part (ii) in Proposition 1. Finally, we note that (A27) implies that $\phi_{i}^{\prime} / u_{c}^{i}=2$ and that this holds in all scenarios under decentralized leadership.

\section{Distortionary taxation: federal fee is proportional to GDP}

To derive Eq. (17) in Corollary 2, we replace $\mathrm{GNI}_{i}$ with $F_{l}\left[L_{i}^{*}\left(t_{i}, t_{j}\right)\right]$ and $\partial \mathrm{GNI}_{i} / \partial t_{i}$ with $w_{i}^{*}\left(\partial L_{i}^{*} / \partial t_{i}\right)$ in (A20). Since the lump-sum tax is not available, (A19) is redundant. Divide (A20) $u_{c}^{i}$. Add and subtract $w_{i}^{*} L_{i}^{*}+t_{i} L_{i}^{*} \partial w_{i}^{*} / \partial t_{i}$, and use (A12). Rearranging and recognizing that the term $\partial s_{i} / \partial t_{i}$ is redundant produce

$$
\left(\frac{\phi_{i}^{\prime}}{u_{c}^{i}}-1\right)\left(w_{i}^{*} L_{i}^{*}+t_{i} L_{i}^{*} \frac{\partial w_{i}^{*}}{\partial t_{i}}\right)+\frac{\phi_{i}^{\prime}}{u_{c}^{i}}\left(t_{i}-s_{i}\right) w_{i}^{*} \frac{\partial L_{i}^{*}}{\partial t_{i}}+\left(l_{i}^{*}-L_{i}^{*}\right) \frac{\partial w_{j}^{n}}{\partial t_{i}}=0
$$

Using the definition $\varepsilon_{i}^{w}=\left(\mathrm{d} w_{i}^{*} / \mathrm{d} t_{i}\right) t_{i} / w_{i}^{*}$, dividing by $w_{i}^{*}$ and solving for $t_{i}$ produce Eq. (17) in the text. To derive Eq. (18), we follow the same procedure as above but note that $\partial s_{i} / \partial t_{i}$ is now present. This produces

$$
\left(\frac{\phi_{i}^{\prime}}{u_{c}^{i}}-1\right)\left(w_{i}^{*} L_{i}^{*}+t_{i} L_{i}^{*} \frac{\partial w_{i}^{*}}{\partial t_{i}}\right)+\frac{\phi_{i}^{\prime}}{u_{c}^{i}}\left(t_{i}-s_{i}\right) w_{i}^{*} \frac{\partial L_{i}^{*}}{\partial t_{i}}+\left(l_{i}^{*}-L_{i}^{*}\right) \frac{\partial w_{j}^{n}}{\partial t_{i}}=\frac{\phi_{i}^{\prime}}{u_{c}^{i}} Y_{i} \frac{\partial s_{i}}{\partial t_{i}}
$$

Replace $\mathrm{GNI}_{i}$ with $F_{l}\left[L_{i}^{*}\left(t_{i}, t_{j}\right)\right]$ and $\partial \mathrm{GNI}_{i} / \partial t_{i}$ with $w_{i}^{*}\left(\partial L_{i}^{*} / \partial t_{i}\right)$ in (A20) and then substitute the resulting expression into (A31). Multiply by $\left(\phi_{i}^{\prime \prime}+\phi_{j}^{\prime \prime}\right)$, divide by $\phi_{j}^{\prime \prime}$ and $w_{i}^{*}$, use $\phi_{i}^{\prime \prime}=\phi_{j}^{\prime \prime}$ and the definition of $\varepsilon_{i}^{w}$. Solving for $t_{i}$ in the resulting expression produces Eq. (18) in the text.

\section{Residence-based taxation: federal fee is proportional to GDP}

When the local governments are able to tax labor income on a residence basis, the local government's budget constraint is modified to read $g_{i}=T_{i}+t_{i} w_{i}^{*}\left(t_{i}, t_{j}\right) l_{i}^{*}$ $\left(t_{i}, t_{j}\right)-s_{i} F_{i}\left[L_{i}^{*}\left(t_{i}, t_{j}\right)\right]$. Solving the federal government's problem in this case and evaluating the comparative static properties of the federal reaction function produce

$$
\frac{\partial s_{i}}{\partial t_{i}}=\frac{\frac{\partial s_{i}}{\partial T_{i}}=\frac{1}{Y_{i}} \frac{\phi_{i}^{\prime \prime}}{\phi_{i}^{\prime \prime}+\phi_{j}^{\prime \prime}}}{Y_{i}\left(w_{i}^{*} l_{i}^{*}+t_{i} l_{i}^{*} \frac{\partial w_{i}^{*}}{\partial t_{i}}+t_{i} w_{i}^{*} \frac{\partial l_{i}^{*}}{\partial t_{i}}-s_{i} w_{i}^{*} \frac{\partial L_{i}^{*}}{\partial t_{i}}\right)-\phi_{j}^{\prime \prime}\left(t_{j} l_{j}^{*} \frac{\partial w_{j}^{*}}{\partial t_{i}}+t_{j} w_{j}^{*} \frac{\partial l_{j}^{*}}{\partial t_{i}}+s_{i} w_{i}^{*} \frac{\partial L_{i}^{*}}{\partial t_{i}}\right)}
$$


The first-order conditions associated with the local government's maximization problem become

$$
\begin{gathered}
\frac{\partial U_{i}}{\partial T_{i}}=\phi_{i}^{\prime}-u_{c}^{i}-\phi_{i}^{\prime} Y_{i} \frac{\partial s_{i}}{\partial T_{i}}=0 \\
\frac{\partial U_{i}}{\partial t_{i}}=\phi_{i}^{\prime}\left(w_{i}^{*} l_{i}^{*}+t_{i} l_{i}^{*} \frac{\partial w_{i}^{*}}{\partial t_{i}}+t_{i} w_{i}^{*} \frac{\partial l_{i}^{*}}{\partial t_{i}}-s_{i} w_{i}^{*} \frac{\partial L_{i}^{*}}{\partial t_{i}}-Y_{i} \frac{\partial s_{i}}{\partial t_{i}}\right) \\
+u_{c}^{i}\left(\left(1-t_{i}\right) l_{i}^{*} \frac{\partial w_{i}^{*}}{\partial t_{i}}-L_{i}^{*} \frac{\partial w_{i}^{*}}{\partial t_{i}}-w_{i}^{*} l_{i}^{*}\right)=0
\end{gathered}
$$

Consider first the noncooperative Nash equilibrium, where $s_{i}$ is treated as exogenous by government $i$, i.e., $\partial s_{i} / \partial T_{i}=\partial s_{i} / \partial t_{i}=0$. Using that (A34) implies $\phi_{i}^{\prime} / u_{c}^{i}=1$ in (A35) and rearranging produce

$$
0=t_{i} w_{i}^{*} \frac{\partial l_{i}^{*}}{\partial t_{i}}-s_{i} w_{i}^{*} \frac{\partial L_{i}^{*}}{\partial t_{i}}+\left(l_{i}^{*}-L_{i}^{*}\right) \frac{\partial w_{i}^{*}}{\partial t_{i}}
$$

Using that the identity $w_{j}^{*}\left(t_{i}, t_{j}\right)=w_{i}^{*}\left(t_{i}, t_{j}\right)$ implies $\partial w_{j}^{*} / \partial t_{i}=\partial w_{i}^{*} / \partial t_{i}$ and solving for $t_{i}$ in the resulting expression produce Eq. (19) in the text.

Turning to the decentralized leader, multiply (A34) by $w_{i}^{*} l_{i}^{*}$ and subtract the resulting expression from (A35). This produces

$$
\begin{aligned}
0= & \phi_{i}^{\prime}\left(t_{i} l_{i}^{*} \frac{\partial w_{i}^{*}}{\partial t_{i}}+t_{i} w_{i}^{*} \frac{\partial l_{i}^{*}}{\partial t_{i}}-s_{i} w_{i}^{*} \frac{\partial L_{i}^{*}}{\partial t_{i}}\right) \\
& +u_{c}^{i}\left(\left(1-t_{i}\right) l_{i}^{*} \frac{\partial w_{i}^{*}}{\partial t_{i}}-L_{i}^{*} \frac{\partial w_{i}^{*}}{\partial t_{i}}\right)-\phi_{i}^{\prime} Y_{i}\left(\frac{\partial s_{i}}{\partial t_{i}}-w_{i}^{*} l_{i}^{*} \frac{\partial s_{i}}{\partial T_{i}}\right)
\end{aligned}
$$

Use (A32) and (A33) to evaluate the expression inside the last pair of brackets

$$
\begin{aligned}
\frac{\partial s_{i}}{\partial t_{i}}-w_{i}^{*} l_{i}^{*} \frac{\partial s_{i}}{\partial T_{i}} & \phi_{i}^{\prime \prime}\left(t_{i} l_{i}^{*} \frac{\partial w_{i}^{*}}{\partial t_{i}}+t_{i} w_{i}^{*} \frac{\partial l_{i}^{*}}{\partial t_{i}}-s_{i} w_{i}^{*} \frac{\partial L_{i}^{*}}{\partial t_{i}}\right)-\phi_{j}^{\prime \prime}\left(t_{j} l_{j}^{*} \frac{\partial w_{j}^{*}}{\partial t_{i}}+t_{j} w_{j}^{*} \frac{\partial l_{j}^{*}}{\partial t_{i}}+s_{i} w_{i}^{*} \frac{\partial L_{i}^{*}}{\partial t_{i}}\right) \\
= & Y_{i}\left(\phi_{i}^{\prime \prime}+\phi_{j}^{\prime \prime}\right)
\end{aligned}
$$

Also substitute (A32) into (A34) and rearrange. This produces $\phi_{i}^{\prime} / u_{c}^{i}=$ $\left(\phi_{i}^{\prime \prime}+\phi_{j}^{\prime \prime}\right) / \phi_{j}^{\prime \prime}=2$. Substituting this equation and (A38) into (A37), simplifying and solving for $t_{i}$ produce Eq. (20) in the text. 


\section{No federal redistribution}

The federal budget constraint $\bar{G}=s F_{i}\left[L_{i}^{*}\left(t_{i}, t_{j}\right)\right]+s F_{j}\left[L_{j}^{*}\left(t_{i}, t_{j}\right)\right]$ implies

$$
\frac{\partial s_{i}}{\partial t_{i}}=-\frac{\bar{G}}{\left(Y_{i}+Y_{j}\right)^{2}}\left(w_{i}^{*} \frac{\partial L_{i}^{*}}{\partial t_{i}}+w_{j}^{*} \frac{\partial L_{j}^{*}}{\partial t_{i}}\right)=-\frac{s}{\left(Y_{i}+Y_{j}\right)}\left(w_{i}^{*} \frac{\partial L_{i}^{*}}{\partial t_{i}}+w_{j}^{*} \frac{\partial L_{j}^{*}}{\partial t_{i}}\right)
$$

The local government's first-order conditions are given by $\phi_{i}^{\prime}-u_{c}^{i}=0$ and

$$
\begin{aligned}
0= & \phi_{i}^{\prime}\left(w_{i}^{*} L_{i}^{*}+t_{i} L_{i}^{*} \frac{\partial w_{i}^{*}}{\partial t_{i}}+t_{i} w_{i}^{*} \frac{\partial L_{i}^{*}}{\partial t_{i}}-s_{i} w_{i}^{*} \frac{\partial L_{i}^{*}}{\partial t_{i}}-Y_{i} \frac{\partial s_{i}}{\partial t_{i}}\right) \\
& +u_{c}^{i}\left(\left(1-t_{i}\right) l_{i}^{*} \frac{\partial w_{i}^{*}}{\partial t_{i}}-L_{i}^{*} \frac{\partial w_{i}^{*}}{\partial t_{i}}-w_{i}^{*} l_{i}^{*}\right)
\end{aligned}
$$

Using $\phi_{i}^{\prime}=u_{c}^{i}$ in (A40) and then solving for $t_{i}$ produces Eq. (27) in the text.

\section{References}

Aronsson, T. (2010). Optimal income taxation and decentralized fiscal federalism. Regional Science and Urban Economics, 40, 187-195.

Aronsson, T., \& Blomquist, S. (2008). Redistribution and provision of public goods in an economic federation. Journal of Public Economic Theory, 10, 125-143.

Aronsson, T., Jonsson, T., \& Sjögren, T. (2006). Environmental policy and optimal taxation in a decentralized economic federation. FinanzArchiv, 62, 437-454.

Aronsson, T., \& Wikström, M. (2001). Optimal taxes and transfers in a multilevel public sector. FinanzArchiv, $58,158-166$.

Boadway, R., \& Keen, M. (1996). Efficiency and the optimal direction of federal-state transfers. International Tax and Public Finance, 3, 137-155.

Boadway, R., Marchand, M., \& Vigneault, M. (1998). The consequences of overlapping tax bases for redistribution and public spending in a federation. Journal of Public Economics, 68, 453-478.

Caplan, A., Cornes, R., \& Silva, E. (2000). Pure public goods and income redistribution in a federation with decentralized leadership and imperfect labor mobility. Journal of Public Economics, 77, 265-284.

Caplan, A., \& Silva, E. (2000). Pure public goods and income redistribution in a federation with decentralized leadership and imperfect labor mobility. Journal of Public Economics, 77, 265-284.

Caplan, A., \& Silva, E. (2011). Impure public goods, matching grant rates and income redistribution in a federation with decentralized leadership and imperfect labor mobility. International Tax and Public Finance, 18, 322-336.

Dahlby, B. (1996). Fiscal externalities and the design of intergovernmental grants. International Tax and Public Finance, 3, 397-412.

Dahlby, B., \& Wilson, L. (2003). Vertical fiscal externalities in a federation. Journal of Public Economics, 87, 917-930.

Itaya, J., Okamura, M., \& Yamagucchi, C. (2008). Are regional asymmetries detrimental to tax coordination in a repeated game setting? Journal of Public Economics, 92, 2403-2411.

Keen, M., \& Kotsogiannis, C. (2002). Does federalism lead to excessively high taxes? American Economic Review, 92(1), 363-370.

Köthenbürger, M. (2002). Tax competition and fiscal equalization. International Tax and Public Finance, 9, 391-408.

Köthenbürger, M. (2004). Tax competition in a fiscal union with decentralized leadership. Journal of Urban Economics, 55, 498-513. 
Köthenbürger, M. (2007). Ex-post redistribution in a federation. Implications for corrective policy. Journal of Public Economics, 91, 481-496.

Kotsogiannis, C. (2010). Federal tax competition and the efficiency consequences for local taxation of revenue equalization. International Tax and Public Finance, 17, 1-14.

Mitsui, K., \& Sato, M. (2001). Ex ante free mobility, ex post immobility, and time consistency in a federal system. Journal of Public Economics, 82, 445-460.

Ogawa, H. (2013). Further analysis on leadership in tax competition: The role of capital ownership. International Tax and Public Finance, 20, 474-484.

Peralta, S., \& van Ypersele, T. (2005). Factor endowments and welfare levels in an asymmetric tax competition game. Journal of Urban Economics, 57(2), 258-274.

Sas, W. (2017). Can fiscal equalization mitigate tax competition? Ad valorem and residence-based taxation in a federation. International Tax and Public Finance, 24, 817-853.

Sato, M. (2000). Fiscal externalities efficient transfers in a federation. International Tax and Public Finance, 7, 119-139.

Silva, E. (2017). Tax competition and federal equalization schemes with decentralized leadership. International Tax and Public Finance, 24, 164-178.

Silva, E., \& Caplan, A. (1997). Transboundary pollution control in federal systems. Journal of Environmental Economics and Management, 34, 173-186.

Smart, M. (1998). Taxation and deadweight loss in a system of intergovernmental transfers. Canadian Journal of Economics, 31(1), 189-206.

Publisher's Note Springer Nature remains neutral with regard to jurisdictional claims in published maps and institutional affiliations. 